(-) institute of development studies

IDS Working Paper

Volume 2022 Number 560

CSP Working Paper 020

Comprehensive Social Protection Programming: What is the Potential for Improving Sanitation Outcomes?

Keetie Roelen and Karol Rodriguez

January 2022 
The Institute of Development Studies (IDS) delivers world-class research, learning and teaching that transforms the knowledge, action and leadership needed for more equitable and sustainable development globally.

The Centre for Social Protection (CSP) supports a global network of partners working to mainstream social protection in development policy and encourage social protection systems and instruments that are comprehensive, long term, sustainable and pro-poor. We produce research on conceptual approaches; design issues, including delivery and targeting; and impacts of different social protection initiatives.

Email: socialprotection@ids.ac.uk

Web: www.ids.ac.uk/programme-and-centre/centre-for-social-protection/

CSP WP020

CSP Working Paper series editor: Stephen Devereux

The Sanitation Learning Hub (SLH) supports learning and sharing across the international sanitation and hygiene sector. It uses innovative participatory approaches to engage with both practitioners and policymakers, and the communities they wish to serve. The SLH's work focuses on enabling the sanitation and hygiene sector to innovate, adapt and collaborate in a rapidly evolving landscape, feeding learning into policies and practice.

\section{institute of} development studies

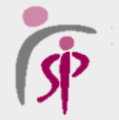

\section{Centre for Social Protection}

(C) Institute of Development Studies 2022
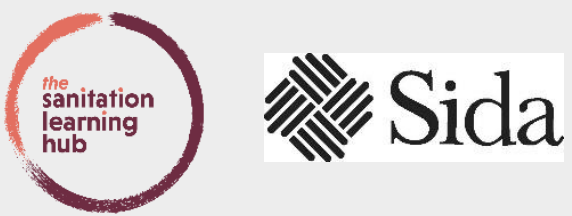

IDS Working Paper Volume 2022 Number 560

CSP Working Paper 020

Comprehensive Social Protection Programming: What is the Potential for Improving Sanitation Outcomes?

Keetie Roelen and Karol Rodriguez

First published by the Institute of Development Studies in January 2022

ISSN: 2040-0209 ISBN: 978-1-78118-909-2 DOI: 10.19088/IDS.2022.001

ORCID ID: Keetie Roelen 0000-0001-7801-3096

Suggested citation: Roelen, K. and Rodriguez, K. (2022) Comprehensive Social Protection Programming: What is the Potential for Improving Sanitation Outcomes?, IDS Working Paper 560, Brighton: Institute of Development Studies, DOI: 10.19088/IDS.2022.001

A catalogue record for this publication is available from the British Library.

This document has been financed by the Swedish International Development Cooperation Agency, Sida. Sida does not necessarily share the views expressed in this material. Responsibility for its contents rests entirely with the authors.

This is an Open Access paper distributed under the terms of the Creative Commons Attribution Non Commercial No Derivatives 4.0 International licence (CC BY-NC-ND), which permits use and distribution in any medium, provided the original authors and source are credited, the work is not used for commercial purposes, and no modifications or adaptations are made.

Available from:

Institute of Development Studies, Library Road

Brighton, BN1 9RE, United Kingdom

+44 (0)1273915637

ids.ac.uk

IDS is a charitable company limited by guarantee and registered in England

Charity Registration Number 306371

Charitable Company Number 877338 
IDS Working Paper

Volume 2022 Number 560

CSP Working Paper 020

Comprehensive Social

Protection Programming:

What is the Potential for

Improving Sanitation

Outcomes?

Keetie Roelen and Karol Rodriguez

January 2022 


\title{
Comprehensive Social Protection Programming: What is the Potential for Improving Sanitation Outcomes?
}

\author{
Keetie Roelen and Karol Rodriguez \\ January 2022
}

\section{Summary}

Millions of people around the world do not have access to adequate sanitation facilities, undermining progress towards Sustainable Development Goal 6.2 that calls for adequate and equitable sanitation for all. Efforts to improve sanitation outcomes have been rapidly accelerated in the past decade alongside an expansion of different financial incentives or subsidies to promote access to services and motivate sanitation behaviour. In parallel, social protection has become part and parcel of development policy, with many low- and middleincome countries now offering some form of cash transfers to those most vulnerable. Comprehensive interventions that couple financial transfers with complementary support such as behaviour change communication, training, or coaching have also grown increasingly popular. Despite similarities between water, sanitation, and hygiene (WASH) subsidy schemes and social protection interventions, these policy areas have largely developed in silos and limited cross-sectoral learning has taken place. This paper begins to fill this knowledge gap by assessing the potential for comprehensive social protection in addressing sanitation outcomes and drawing out policy implications for the social protection and WASH communities. It does so by focusing on a social protection programme in the context of extreme poverty in rural Haiti.

\section{Keywords}

Social protection; sanitation; WASH; cash transfers; targeted subsidies; Haiti. 


\section{Authors}

Keetie Roelen is a Research Fellow and Co-Director of the Centre for Social Protection at the Institute of Development Studies (IDS), University of Sussex. A development economist by training, current research interests include social protection, and the effectiveness of social protection and anti-poverty policies in reducing vulnerability and enhancing wellbeing.

Karol Rodriguez is a PhD student in Economics of Development at Maastricht University, United Nations University - Maastricht Economic and Social Research Institute on Innovation and Technology (UNU-MERIT). Her research focuses on how public policy can shape household and children's wellbeing, with a focus on social protection, nutrition, and early childhood development interventions in both low- and middle-income countries. 


\section{Executive Summary}

Despite Sustainable Development Goal (SDG) 6.2 calling for 'adequate and equitable sanitation for all by 2030', less than half of the world's population uses a safely managed sanitation service and open defecation remains widespread. To achieve the human right of accessible, affordable, safe, and dignified sanitation, the last decade saw an expansion of efforts to improve water, sanitation, and hygiene (WASH) outcomes, including subsidies and other mechanisms. It has been increasingly recognised that traditional efforts that focus on supplying 'hardware' or more recent demand-driven approaches such as empowering communities and changing behaviours can benefit from additional economic support. Targeted subsidies and financial incentives are now widely used within the WASH sector but with mixed success.

The social protection sector relies heavily on provision of financial incentives with targeted cash transfer programmes having expanded rapidly across low- and middle-income countries (LMICs) in the last two decades. More recently, cash transfers are combined with other forms of support such as behaviour change communication, referral mechanisms and additional in-kind support. This type of bundled intervention has been found to reduce hunger, increase access to services and improve psychosocial wellbeing. Despite the resemblance of this type of intervention to bundled interventions in the WASH sector, very little is known about their impact on sanitation outcomes. Interventions in both policy areas have largely developed in silos with limited cross-sector collaboration and learning.

This paper assesses the impact of a comprehensive social protection intervention - the Chemen Lavi Miyò (CLM) programme - on access to sanitation and sanitation practices among women in extreme poverty in rural Haiti. It adopts a mixed methods approach, using quantitative impact evaluation data and qualitative data collected between 2017 and 2019 in Central Plateau in Haiti. Given the programme's focus on women, the paper also contributes to evidence on the links between women's empowerment and sanitation practices, which is still relatively nascent.

Findings suggest that a comprehensive social protection intervention such as the CLM programme has the potential to change access to sanitation and sanitation practices. Participation in the programme increases access and use of improved toilet facilities, and qualitative data suggests that these new facilities are also used by all members of the household. The programme does not significantly change access to or use of sources of drinking water. Spring water remains the main source of drinking water, with supply-side constraints hampering the ability to diversify to other sources of drinking water. The programme may still increase 
the consumption of treated water through its provision of a water filter and consistent follow-up on its usage.

Findings also contribute to literature within both the WASH and social protection sectors on the interplay between women's empowerment, their roles as primary caregivers, and achievement of intended outcomes. Interventions in both sectors may be more effective when targeting women to leverage their positions as primary caregivers. However, doing so may also increase already high levels of drudgery for women. Qualitative data shows how women struggle to combine their many responsibilities, especially in undertaking paid work and unpaid care. In terms of sanitation and hygiene practices, women reported difficulties in maintaining good practices especially when having to leave children in the care of others.

This paper also highlights the importance of context. Lack of impact on diversification of sources of drinking water was in large part due to supply-side constraints. The remoteness of our study locations coupled with poor provision of public or affordable water services severely hampered the potential effect of an intervention such as the CLM programme.

Overall, this paper bridges debate and practice across policy divides of social protection and WASH, opening a conversation about their mutually reinforcing nature. Both sectors have widespread experience with the implementation of financial incentives, such as in the form of targeted subsidies or cash transfers. Furthermore, emerging evidence in both sectors points to the potential of bundled interventions that combine behaviour change components with economic support. Cross-sectoral learning and collaboration could help to break silos and make interventions more effective. We identify various entry points for doing so, based on design and implementation issues that cut across sectors. These include the processes of targeting support, identifying eligible beneficiaries, changing behaviours, assessing needs, and monitoring change. 


\section{Contents}

Acknowledgements

1. Introduction

2. Literature review

2.1 Financial incentives in WASH

2.2 Cash transfers in social protection

2.3 Gender in WASH and social protection

3. Case study

$3.1 \quad$ Haiti

3.2 CLM programme

4. Methodology

4.1 Research design

4.2 Quantitative data analysis

4.3 Qualitative data analysis

5. Findings

5.1 Quantitative findings

$\begin{array}{llr}5.2 & \text { Qualitative findings } & 28\end{array}$

$\begin{array}{lll}\text { 5.2.1 Perceived programme effects } & 29\end{array}$

$\begin{array}{lll}5.2 .2 & \text { Challenges to impact } & 31\end{array}$ 
6. Conclusion and implications for policy

6.1 Overview of empirical findings

6.2 Contributions to literature

6.3 Implications for policy

6.3.1 Implement context-appropriate combination of interventions

6.3.2 Pay closer attention to women's roles

6.3.3 Build and strengthen cross-sectoral linkages

\section{Figures}

Figure 4.1 Timeline of data collection vis-à-vis programme implementation

Figure 5.1 Types of toilet facilities used by treatment and control groups at baseline and endline 24 Figure 5.2 Types of sources of drinking water used by treatment and control groups at baseline and endline

\section{Tables}

Table 4.1 Demographic characteristics at baseline

Table 5.1 Descriptive statistics about use of improved toilet facilities at baseline

Table 5.2 Programme impact on use of improved toilet facilities

Table 5.3 Descriptive statistics about use of improved sources of drinking water at baseline 


\section{Acknowledgements}

This document has been financed by the Swedish International Development Cooperation Agency, Sida. Sida does not necessarily share the views expressed in this material. Responsibility for its contents rests entirely with the authors.

The authors thank two anonymous reviewers for their valuable feedback.

\section{Acronyms}

$\begin{array}{ll}\text { BCC } & \text { behaviour change communication } \\ \text { CLM } & \text { Chemen Lavi Miyò } \\ \text { CLTS } & \text { Community-Led Total Sanitation } \\ \text { DiD } & \text { difference-in-differences } \\ \text { FGD } & \text { focus group discussion } \\ \text { IDS } & \text { Institute of Development Studies } \\ \text { JMP } & \text { WHO/UNICEF Joint Monitoring Programme for Water Supply, } \\ & \text { Sanitation and Hygiene } \\ \text { KII } & \text { key informant interview } \\ \text { LMICs } & \text { low- and middle-income countries } \\ \text { SDG } & \text { Sustainable Development Goal } \\ \text { UN } & \text { United Nations } \\ \text { UNICEF } & \text { United Nations Children's Fund } \\ \text { WASH } & \text { water, sanitation, and hygiene }\end{array}$




\section{Introduction}

The 'world is alarmingly off-track to deliver sanitation for all by 2030' (UNICEF and WHO 2020: 11). To achieve the human right of accessible, affordable, safe, and dignified sanitation, progress towards Sustainable Development Goal (SDG) 6.2 must be rapidly accelerated. It has been increasingly recognised that conventional efforts that focus on creating demand for sanitation, empowering communities, and changing behaviours can benefit from additional, external support (Kohlitz, Carrard and Willetts 2019). Such support mechanisms can take a variety of forms including microloans, cash rebate after building latrines, discount vouchers to purchase sanitation-related products, setting up savings and lending associations (e.g. revolving funds), and assistance to community leaders to pool resources at community level to assist disadvantaged households (ibid.). While some are implemented at community level, with community leaders or representatives acting as facilitators, most are targeted at household level.

Targeted subsidies to poor households for whom the economic costs associated with accessing water and sanitation services are a prohibiting factor for changing their behaviour is a widely used mechanism to ensure universal access (Andres et al. 2019). Their success has been mixed: subsidies can cover the affordability gap and ensure individuals' ability and willingness to pay for sanitation services, but they are only effective if well-targeted and if they benefit the poorest and most vulnerable (UNICEF and WHO 2020). The relevance of subsidies also depends on context: costs of latrines tend to be higher in urban areas and are therefore more likely to prevent the poor from using sanitation facilities (Myers 2014). Others have raised concerns about external support crowding out community-led action and have argued the need for hybrid approaches that strengthen and build on intra-communal support. External mechanisms, such as subsidies, should be used when necessary and appropriate, without them undermining intra-communal support (Myers et al. 2017).

Strikingly absent from research and debates about the use and effectiveness of targeted household-level subsidies to lift financial constraints to improving WASH outcomes is the overlap with another policy area that relies heavily on this type of mechanism, namely social protection. Social protection has become integral to development policy in the last two decades (Devereux et al. 2016), as evidenced by its embeddedness in the SDGs, with SDG 1.3 calling for the implementation of nationally appropriate social protection systems by 2030 (UNDESA 2021). While there has been some acknowledgement of the overlap between social protection and ensuring access to affordable sanitation services (UNRISD 2016), these policy areas have largely developed in silos. 
Comprehensive Social Protection Programming: What is the Potential for Improving Sanitation Outcomes?

Social protection interventions such as cash transfers and comprehensive programmes that combine economic support with behaviour change interventions have grown particularly popular. A widening evidence base attests to wide-ranging positive impacts, including reduced hunger, greater uptake of education and health services, and improved psychosocial wellbeing (Banerjee et al. 2015; Bastagli et al. 2019; Roelen et al. 2020). Evidence on the impact on WASH outcomes is relatively limited. Nevertheless, comprehensive schemes have strong potential to improve WASH outcomes by removing financial and social barriers (Renzaho et al. 2018). Indeed, various evaluations confirm the impact of cash transfers on the use of improved water and sanitation (de Groot et al. 2017). In Nepal, for example, the provision of regular transfers alongside wider capacity building and behaviour change interventions had a positive impact on use of improved sources for drinking water and sanitation facilities as well as on disposal of children's faeces (Renzaho et al. 2018). Nevertheless, despite the rise of these schemes and the concurrent investment in their evaluation, very little is known about their impact on sanitation and WASH indicators (Renzaho et al. 2018).

In this paper, we aim to contribute to knowledge about whether and how comprehensive social protection programming might contribute towards improving WASH outcomes. In doing so, we aim to draw linkages between two related policy fields that have largely developed separately despite strong overlaps in types of support provided and envisaged impacts. Using quantitative impact evaluation data and qualitative data collected between 2017 and 2019 in rural Haiti, we assess the impact of a comprehensive programme - Chemen Lavi Miyò (CLM) - on access to improved water and sanitation for women in extreme poverty. Given the programme's focus on women, the paper also seeks to contribute to evidence on the links between women's empowerment and sanitation practices, which is still relatively nascent (Hirai, Graham and Sandberg 2016). It bridges debate and practice across policy divides of social protection and $\mathrm{WASH}$, opening a conversation about their mutually reinforcing nature and how cross-sectoral learning and collaboration could be strengthened. 


\section{Literature review}

In this section we provide a review of literature on targeted financial incentives in WASH and social protection sectors, and the theme of gender in both policy areas.

\subsection{Financial incentives in WASH}

Subsidies and financial incentives are used in WASH and can take a variety of forms. Supply-side subsidies constitute resources granted to producers of services, while demand-side subsidies aim to foster access to and take-up of such services (Narzetti and Marques 2020). Demand-side, or consumer subsidies, are often targeted - either implicitly or explicitly -, seeking to improve affordability for poorer consumers (Komives et al. 2005). They may be implemented through the tariff structure by decreasing consumer prices, can appear as a discount to household bills, or be paid directly to households in the form of cash transfers (ibid.).

The use of targeted subsidies within the rural sanitation sector has been the subject of long-standing debate. Arguments in favour of subsidies can be made on moral and economic grounds (Evans, van den Voorden and Peal 2009). From an equity perspective, it is unfair that poorer households are unable to afford basic sanitation while richer families can access services at lower cost in their own homes. One could argue that governments have a moral duty to provide basic services that are affordable for everyone (ibid.). From an economic point of view, subsidies can incentivise people to access sanitation services, especially when they have insufficient information about the benefits of doing so or underappreciate the benefits of individual action for society as a whole (ibid.). In addition, lack of affordability is a well-documented obstacle to adoption of improved sanitation facilities (Mara et al. 2010), with targeted subsidies an increasingly popular mechanism for improving sanitation behaviour and outcomes.

There is some evidence showing that monetary incentives - especially when combined with existing behavioural interventions - can change sanitation behaviour and improve outcomes over and above impacts of behaviour change interventions alone. A study from Ghana shows that the provision of welltargeted subsidies, in the form of vouchers, to the poorest households can render community-oriented behaviour change approaches such as CommunityLed Total Sanitation (CLTS) more effective (Radin et al. 2020). When comparing costs and benefits associated with a 'traditional' CLTS-only intervention and a CLTS-plus intervention, authors found that net benefits of the plus variant are higher compared to the CLTS-only approach in reducing open defecation (ibid.). 
This finding is in line with research in Bangladesh and India, which also demonstrated that supplementing CLTS with targeted vouchers or subsidies can make the approach more effective in decreasing open defecation (Guiteras, Levinsohn and Mobarak 2015; Hammer and Spears 2016). Similarly in Lao People's Democratic Republic, a clustered randomised control trial found that combining CLTS with financial incentives at household level increased sanitation uptake among the poor. By contrast, providing village-level incentives primarily increased uptake among the non-poor (Cameron et al. 2021). It should be noted that in all cases, part of the higher positive effect of the combined intervention could be attributed to positive health spillovers due to larger proportions of the community improving their sanitation practices. Some studies suggest that subsidies also need to be substantial in size to achieve their desired effect. For example, a randomised control trial in the Philippines similarly found that large, subsidised loans increased construction of improved toilet facilities while a loan with a small subsidy did not (Batmunkh et al. 2019).

Notwithstanding these findings, there are also concerns about the use of subsidies within the WASH sector due to a long history of past failures of projects subsidising sanitation hardware to poor households while at the same time ignoring the need for behaviour change as well as operation and maintenance of latrine technologies. Furthermore, at household level, poor targeting can lead to 'inclusion errors' with subsidies ending up with more wealthy households than intended (Evans et al. 2009). Research provides evidence for this concern, suggesting that many subsidies are poorly targeted, with on average more than half of subsidies captured by richest population quintile (Andres et al. 2019). Creation of dependency and lack of ownership lowering the chance of sustainable use is another widely held concern (Evans et al. 2009; Robinson and Gnilo 2016). At sector level, subsidies have also been criticised for being unaffordable for donors and governments, for distorting the market, for stifling innovation, and for facilitating rent seeking by governments and service providers (Andres et al. 2019; Evans et al. 2009).

\subsection{Cash transfers in social protection}

Experiences with targeted consumer subsidies, especially when implemented in conjunction with other interventions, mirror practice and evidence from within the realm of social protection. The United Nations Children's Fund (UNICEF) defines social protection as '(A) set of policies and programmes aimed at preventing or protecting all people against poverty, vulnerability and social exclusion throughout their life-course, with a particular emphasis towards vulnerable groups' (UNICEF 2019: 2). Interventions commonly consist of social assistance that protects the poorest and vulnerable against deprivation, social insurance that prevents individuals from falling into poverty, and labour market policies that promote livelihood strengthening and employment. More recently, interventions 
Comprehensive Social Protection Programming: What is the Potential for Improving Sanitation Outcomes?

have expanded to offer complementary types of support and serve multiple objectives.

So-called 'cash plus' interventions are a form of comprehensive social protection that provide cash transfers (or subsidies) and complement these various other types of support (Roelen et al. 2017). These schemes have grown increasingly popular in the last 5-10 years, in large part as a result of the wide evidence base on cash transfers that points to the success of giving cash (Bastagli et al. 2019) but also suggests that people in poverty need more comprehensive support to address the multidimensional nature of poverty. The 'plus' components that complement cash transfers often seek to incentivise behaviour change or address supply-side constraints. They can be provided as inherent components of the scheme itself (e.g. information provision, psychosocial support, additional in-kind transfers) or by establishing cross-sectoral linkages (e.g. referrals to health services, health insurance, or tuition fee waivers) (Roelen et al. 2017). In Tanzania, for example, a 'cash plus' programme aiming to improve outcomes for adolescents combines cash transfers with livelihood skills, training, and education on sexual and reproductive health (Transfer Project 2018). In Ghana, beneficiaries of Livelihood Empowerment Against Poverty (LEAP) received fee waivers for the National Health Insurance Scheme (NHIS), thereby incentivising uptake of health insurance among poor households (Palermo et al. 2019).

A recent systematic review of the impact of 'cash plus' programmes over and above the provision of cash alone indicates positive impact on sanitation behaviour (Little et al. 2021). In line with findings within the sanitation literature, the provision of financial support in conjunction with other measures such as behaviour change communication (BCC) led to reductions in open defecation, improved handwashing practices, and treating drinking water (ibid.). Commonly these 'cash plus' programmes are focused on improving child health and nutrition, with sanitation as a key mechanism through which to achieve impacts (as opposed to viewing changes in sanitation behaviour as a goal in and of itself). In Myanmar, for example, the 'cash plus' intervention focused on improving maternal and infant health, targeting its support to women at the beginning of their pregnancy up until their children reached two years of age (Field and Maffioli 2021). There are also examples of interventions explicitly integrating WASH components. In the Philippines, for example, the flagship conditional cash transfer Pantawid Pamilyang Pilipino Program (4P) included hygiene and sanitation messaging, various CLTS triggering tools, and low-cost sanitation options in rural areas (CLTS Knowledge Hub 2016). 


\subsection{Gender in WASH and social protection}

Gender is a theme that cuts across the literature on sanitation practices and 'cash plus' programming. Women may be more compelled to improve sanitation in the household. Shame and stress associated with menstrual hygiene management (Mahon and Fernandes 2010) and risk of sexual violence when defecating away from home (Lennon 2011) are important reasons for women to invest in a sanitation facility close to home. Having more children may also result in families prioritising the need for a sanitation facility to dispose of children's faeces and ensure their health, and giving women - as primary caregivers greater leverage over sanitation decisions (Hirai et al. 2016). There is some evidence that suggests that greater gender equity results in households improving their sanitation conditions. Research in Kenya showed that greater female decision-making power over large household expenditures is associated with improved sanitation (ibid.).

Women's roles and the ways in which they prioritise expenditures and behaviours that benefit children's development and health is also a recurrent theme within social protection, and 'cash plus' programming especially. Literature on gender-sensitive social protection has extensively explored how programmes can address gender inequities and improve or undermine women's empowerment, such as through payment of transfers to women directly (Holmes and Jones 2013). The evidence is mixed: while findings suggest that transfers can reduce intimate partner violence (Buller et al. 2016), attaching conditions to the receipt of cash transfers, such as requiring children to have health checkups, adds to women's time burden and stress (Holmes and Jones 2013; Cookson 2018).

The latter is a recurrent issue in schemes that aim to achieve behaviour change and channel their activities through women to be most effective. For example, 'cash plus' programmes that seek to reduce child malnutrition are almost exclusively focused on women, seeking to improve their autonomy to making better choices with respect to diets for their children (de Groot et al. 2017). This instrumental inclusion of women is problematic for two reasons. First, it reaffirms women's roles as main caregivers and reinforces existing gender norms in relation to unpaid work and caregiving. Second, and relatedly, directing all efforts to women can reinforce drudgery and perpetuate the combined burden of paid and unpaid work for women (Chopra and Zambelli 2017). The notion that women pay more attention to sanitation and that greater autonomy may result in better sanitation practices may give rise to similar concerns for sanitation programming, and for the use of targeted subsidies as part of those. 


\section{Case study}

In this section we provide some background information about the context in rural Haiti and provide information about the CLM programme.

\subsection{Haiti}

Haiti is the poorest country in the Americas and one of least developed countries in the world. It ranks 163rd (out of 188) based on the 2016 Human Development Index (UNDP 2017). Poverty is widespread: the most recent monetary poverty estimates indicate that 59 per cent of Haitians were living under the national poverty line of US $\$ 2.42$ per day in 2012 (World Bank 2018) and that 41 per cent of the population were experiencing multidimensional poverty in 2016/17 (UNDP 2019). Recent episodes of political and institutional instability as well as the fallout of the Covid-19 pandemic are likely to have increased poverty (World Bank 2020).

The large majority of Haitians do not have access to improved hygiene and sanitation. Haiti also has high levels of open defecation and use of unimproved water sources, especially in rural areas (see JMP 2021). In 2020, 31.5 per cent of the population practised open defecation and another 25.9 per cent used unimproved sanitation facilities. Fourteen per cent reported no handwashing facilities while a further 70.5 per cent listed limited services for hygiene. Roughly half of the population consumed water from unimproved sources. In short, Haiti is off track to meet the SDG 6.2 by 2030 .

Poor sanitation coupled with low access to quality health services and high levels of deprivation underpin one of the highest rates of infant mortality in the world. The neonatal mortality rate was 25 per 1,000 births in 2011 (Cianelli et al. 2014), nearly one in 12 children died before reaching the fifth year in 2012 (IHE and ICF 2018) and almost 22 per cent of all children under five were stunted in 2017 (Independent Expert Group of the Global Nutrition Report et al. 2020). Research sites included in this study were located in two of the poorest departments in the country, namely Centre and Artibonite (IMF 2014).

The country's long history of political instability, generally weak governance, low levels of public service provision and vulnerability to natural disasters dampen efforts to improve people's lives, including in relation to WASH and health. The cholera outbreak following the 2010 earthquake is a case in point; despite the country not having had any confirmed cases of cholera for more than a century prior to the earthquake, the country reported 805,000 suspected cases and almost 9,500 deaths following the outbreak. The disease was traced back to a United Nations (UN) peacekeeping mission in the central part of the country 
Comprehensive Social Protection Programming: What is the Potential for Improving Sanitation Outcomes?

(Piarroux and Frerichs 2015). The Independent Panel investigating the outbreak found that it resulted from the confluence of simultaneous deficiencies in water, sanitation, and health-care systems, and conducive environmental and epidemiological conditions (Lantagne et al. 2014). Although the country has had no reported cases of cholera in recent years (World Bank 2021), continued political unrest following the assassination of President Jovenel Moïse in July 2021 and another devastating earthquake in the southwest of the country in September 2021 point to continued obstacles for establishing safe and healthy livelihoods.

\subsection{CLM programme}

The CLM programme has been implemented by the non-governmental organisation Fonkoze in central Haiti since it was first piloted in 2007. The programme supports women from extremely poor households over a period of 18 months, helping them to improve wellbeing and build sustainable livelihoods. Programme selection is based on an intricate process of social mapping, participatory wealth ranking and final verification. Research about targeting efficiency has found that the programme includes those most vulnerable in the communities that are served (Greeley 2019).

Female participants receive intensive and tailored support, including: (i) weekly stipends of 350 gourdes (approximately US\$4) during the first six months of implementation, (ii) asset transfer (primarily rearing goats or pigs), (iii) support to join a Village Savings and Lending Association (VSLA), (iv) home visits by case managers, including health and nutrition messaging, and (v) in-kind support such as housing materials and access to the local hospital. BCC offered as part of the programme include messaging in relation to healthy diets and eating habits, clean drinking water, and sanitation and hygiene. The CLM programme also supports children with necessary treatment, fortified foods and nutrient supplements when identified as severely malnourished.

With respect to sanitation, the most pertinent programme components relate to direct provision of materials for families to build a pit latrine (although they must find support from within the community to help them build the latrine) and include messaging about washing hands after defecation and before cooking meals, building and using their latrines, and keeping their children clean. The programme also provides a ceramic water filter and jug at the start of the programme and promotes other water treatment methods such as boiling and sunlight exposure. 


\section{Methodology}

Before discussing our research design and research methods, we detail our research questions.

The overarching question is: Can a comprehensive social protection intervention promote access to and use of improved sanitation services and water sources?

In support of this overall questions, sub-questions include:

- Can a comprehensive social protection intervention improve access to and use of improved toilet facilities?

- Can a comprehensive social protection intervention improve access to and use of improved drinking water?

- What factors contribute to or hamper access to and use of improved sanitation, including gender?

\subsection{Research design}

This paper employs a mixed methods approach, using quantitative evaluation data and in-depth qualitative data that was collected between 2017 and 2019. A mixed methods approach was chosen as it allows us to unpack the 'black box' of programme impact (or lack thereof) (Quisumbing et al. 2020) and, as a result, produce insights that are particularly relevant for policy and practice (de Haan, Dowie and Mariara 2020). Research adhered to ethical protocol, including informed consent, anonymity in data analysis and dissemination, and respectful conduct in the field. Ethical approval was provided by the Research Ethics Committee at IDS.

Figure 4.1 provides an overview of the timing of data collection activities vis-à-vis implementation of various programme components. Quantitative and qualitative data collection took place over a period of 24 months between June 2017 and June 2019. We provide a brief overview of quantitative and qualitative methods used in this study. ${ }^{1}$ 


\section{Figure 4.1 Timeline of data collection vis-à-vis programme implementation}

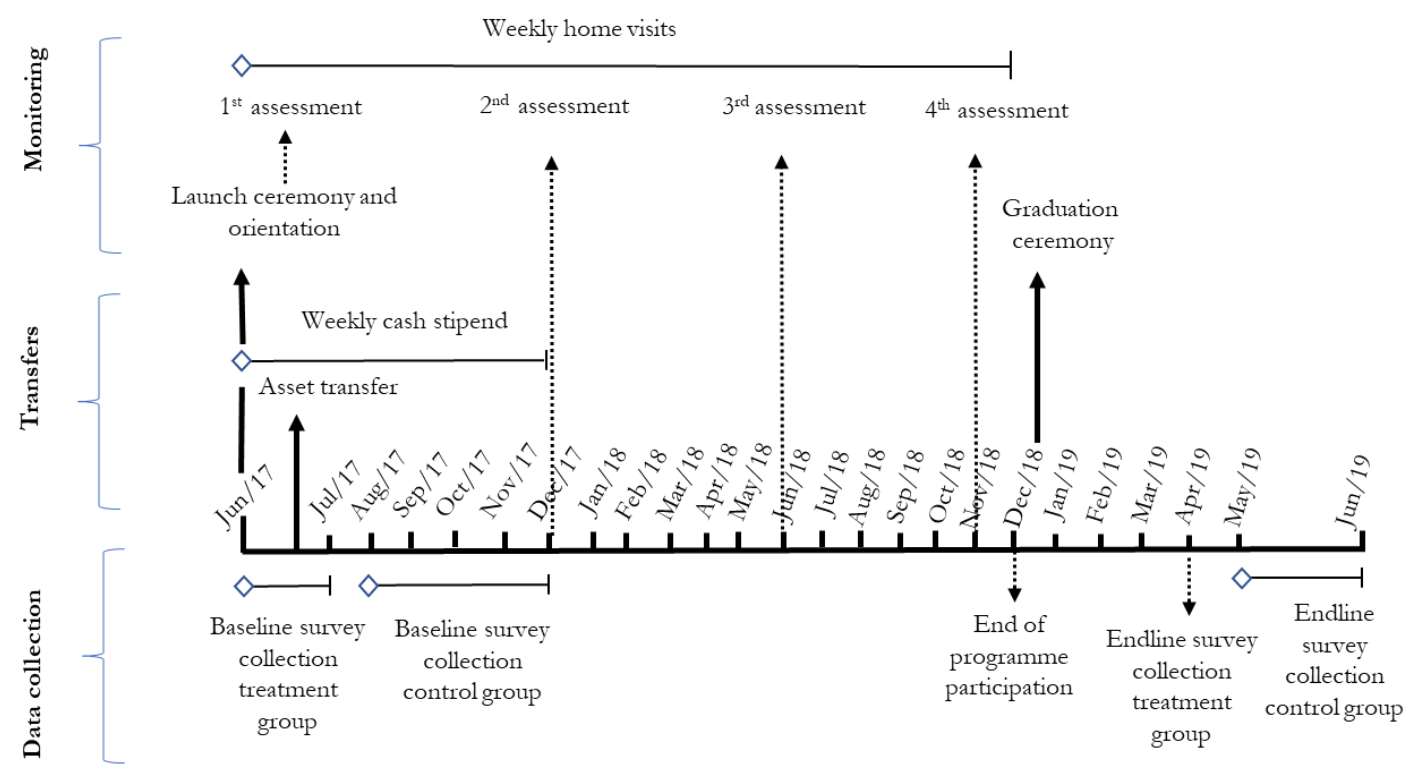

Source: Authors' own

\subsection{Quantitative data analysis}

The quantitative component of the evaluation is based on a quasi-experimental approach. The control group was sampled from other communities in the Central Plateau region by (i) selecting neighbourhoods similar to those where the programme took place; and (ii) identifying women with similar living conditions as programme participants. Sampling procedures for the control group mirrored the targeting process for the CLM programme by employing social mapping and participatory wealth rankings.

The baseline sample (see Table 4.1) includes 1,168 households, out which 561 households participate in the CLM programme and belong to the treatment group and 607 households are part of the control group. Characteristics such as the age of the primary female and the share of female members in the household seem to be equal for households in both groups. However, we also observe some significant differences between treatment and control groups in household size, wealth index, and some family structure covariates (i.e. proportion of ill members in the household, proportion of members aged between 15 and 60, and the proportion of children aged five and under). Significant differences between the treatment and control groups for various characteristics may lead to bias in our impact estimates. We address this by employing a quasiexperimental approach, which involves a three-step econometric procedure (Angrist and Pischke 2008) that includes (i) constructing a valid counterfactual or control group, (ii) matching CLM participants in the treatment group with non- 
participants in the control group, and (iii) estimating average treatment effects of the programme.

\section{Table 4.1 Demographic characteristics at baseline}

\begin{tabular}{|c|c|c|c|c|c|c|}
\hline & \multicolumn{3}{|l|}{ Means } & \multicolumn{3}{|c|}{ Differences } \\
\hline & Panel & Treatment & Control & $\begin{array}{l}\text { Control- } \\
\text { treatment }\end{array}$ & t-stat & p-value \\
\hline \multicolumn{7}{|l|}{$\begin{array}{l}\text { Household-level } \\
\text { covariates }\end{array}$} \\
\hline Age of the primary female & 34.03 & 34.14 & 33.92 & -0.23 & -0.33 & 0.74 \\
\hline Household size & 5.16 & 5.37 & 4.97 & -0.41 & -3.52 & $0.00^{\star \star \star}$ \\
\hline $\begin{array}{l}\text { \% ill members in the } \\
\text { household }\end{array}$ & 0.41 & 0.51 & 0.32 & -0.19 & -10.17 & $0.00^{\star \star *}$ \\
\hline$\%$ members aged $(15-60)$ & 0.13 & 0.16 & 0.10 & -0.07 & -3.32 & $0.00^{\star \star *}$ \\
\hline $\begin{array}{l}\% \text { members five years or } \\
\text { younger }\end{array}$ & 0.23 & 0.25 & 0.21 & -0.04 & -3.41 & $0.00^{* * *}$ \\
\hline $\begin{array}{l}\text { Two parents in the } \\
\text { household }\end{array}$ & 0.68 & 0.71 & 0.64 & -0.07 & -2.45 & $0.01^{* *}$ \\
\hline $\begin{array}{l}\% \text { females in the } \\
\text { household }\end{array}$ & 0.53 & 0.53 & 0.54 & 0.01 & 1.02 & 0.31 \\
\hline Wealth index & 2.81 & 2.51 & 3.09 & 0.58 & 7.10 & $0.00^{\star * \star}$ \\
\hline $\begin{array}{l}\text { Number of } \\
\text { observations }\end{array}$ & 1,168 & 561 & 607 & & & \\
\hline
\end{tabular}

Note: *significant at $10 \% ;{ }^{* *}$ significant at $5 \% ;{ }^{* * *}$ significant at $1 \%$.

Source: Authors' own.

The survey included questions about the type of toilet facilities and the main source of drinking water. Regarding toilet facilities responses were classified as improved or unimproved; improved facilities include flush, pit latrine with slab, traditional pit latrine and composting toilet while unimproved facilities included pit latrine without slab, bucket toilet, hanging toilet, or the absence of toilet facilities. In reference to the World Health Organization (WHO)/UNICEF Joint Monitoring Programme for Water Supply, Sanitation and Hygiene (JMP) global monitoring ladder for sanitation, this quantitative data allows us to consider programme impact at level of 'basic service' (i.e. private improved facility which separates excreta from human contact) rather than 'safely managed services' (i.e. private improved facility where faecal wastes are safely disposed on site or transported and treated off-site; plus a handwashing facility with soap and water) (WHO 2016).

With respect to drinking water, improved sources include a private faucet, public standpipe (provided through DINEPA - National Directorate of Potable Water 
Comprehensive Social Protection Programming: What is the Potential for Improving Sanitation Outcomes?

and Sanitation), well or tube well, or water obtained from kiosk, truck, bottle, bag, bucket, or jerrycan. Unimproved sources of drinking water include artesian well or borehole, spring water, rainwater, surface water from rivers, stream, dam, lakes, ponds, canals or irrigation channel, and untreated water.

It should be noted that quantitative data on sanitation and water is collected at household level; we are therefore unable to consider differential impacts depending on gender or age of individuals, for example.

\subsection{Qualitative data analysis}

The qualitative data component of this study is based on case studies of programme participants, providing insights across age, spousal relationships, and progress in the programme; focus group discussions (FGDs) with programme participants, their family members, and community members; as well as key informant interviews (KIIs) and group conversations with programme staff. Various participatory tools such as family mapping, daily activity clock, body map, programme component scoring, and community mapping exercises were incorporated in case study, FGD, and KII activities as appropriate. Data were collected between February and April 2018 and included 24 case studies, 30 FGDs and seven KIls and group conversations. In total, the qualitative data includes 215 respondents.

Thematic analysis was undertaken using a structured coding scheme. The scheme was developed during a research analysis workshop in September 2018 and grounded in conceptual frameworks and themes that emerged during fieldwork and first reading of transcripts. Given the focus of the original research, top-nodes focused on key elements of child development (e.g. nutrition, health, safety and security), hypothesised pathways (e.g. income effect, training effect) as well as thematic categories such as paid work and unpaid work of women. Coding was undertaken by three Research Officers using NVivo, working together to ensure consistency across.

The coding scheme also included a separate top-node and detailed nodes in relation to sanitation and water. They pertain to access to and use of water and sanitation facilities, whether the CLM programme changed sanitation practices and how, and whether sanitation behaviour is liable to seasonal effects or other changes. Qualitative data also includes information about the use of private improved sanitation facilities in conjunction with handwashing facilities that include water and soap, providing some insight into adherence to 'safely managed services' according to the JMP ladder for sanitation and as monitored for SDG 6.2 on accessible and equitable sanitation for all (WHO 2016). This data was re-analysed for the purposes of this paper. 


\section{Findings}

We present our quantitative and qualitative findings in turn.

\subsection{Quantitative findings}

We explore impact on use of improved toilet facilities and improved sources of drinking water.

In terms of sanitation (Figure 5.1), we observe that the large majority of households had no facility and practised open defecation. Around 83 per cent of households in the treatment group and 63 per cent of households in the control group did not use toilet facilities. Among households who did use toilet facilities, pit latrine with slab, traditional latrine and pit latrine without slab are among the most common in the treatment group. We observe a shift in the use of toilet facilities over the course of the programme period for the treatment group. At endline, almost 70 per cent of CLM participants had a pit latrine with slab. In contrast, the proportion of non-beneficiary households using this type of facility slightly increased from baseline to endline 11 per cent to 19 per cent respectively.

Table 5.1 displays differences between baseline and endline for CLM beneficiaries (treatment group) and the control group. Large proportions of households in the treatment and control groups use poor or unimproved toilet facilities at baseline. Around 94 per cent of CLM programme beneficiaries have poor facilities at baseline while this is around 80 per cent for the control group. At endline, there is an improvement in toilet facilities, above 70 per cent of programme participants improved their toilet facilities. In comparison, a significantly lower proportion (25 per cent) of households in the control group improved their toilet facilities. The difference between baseline and endline is only significant for the treatment group. 


\section{Figure 5.1 Types of toilet facilities used by treatment and control groups at baseline and endline}

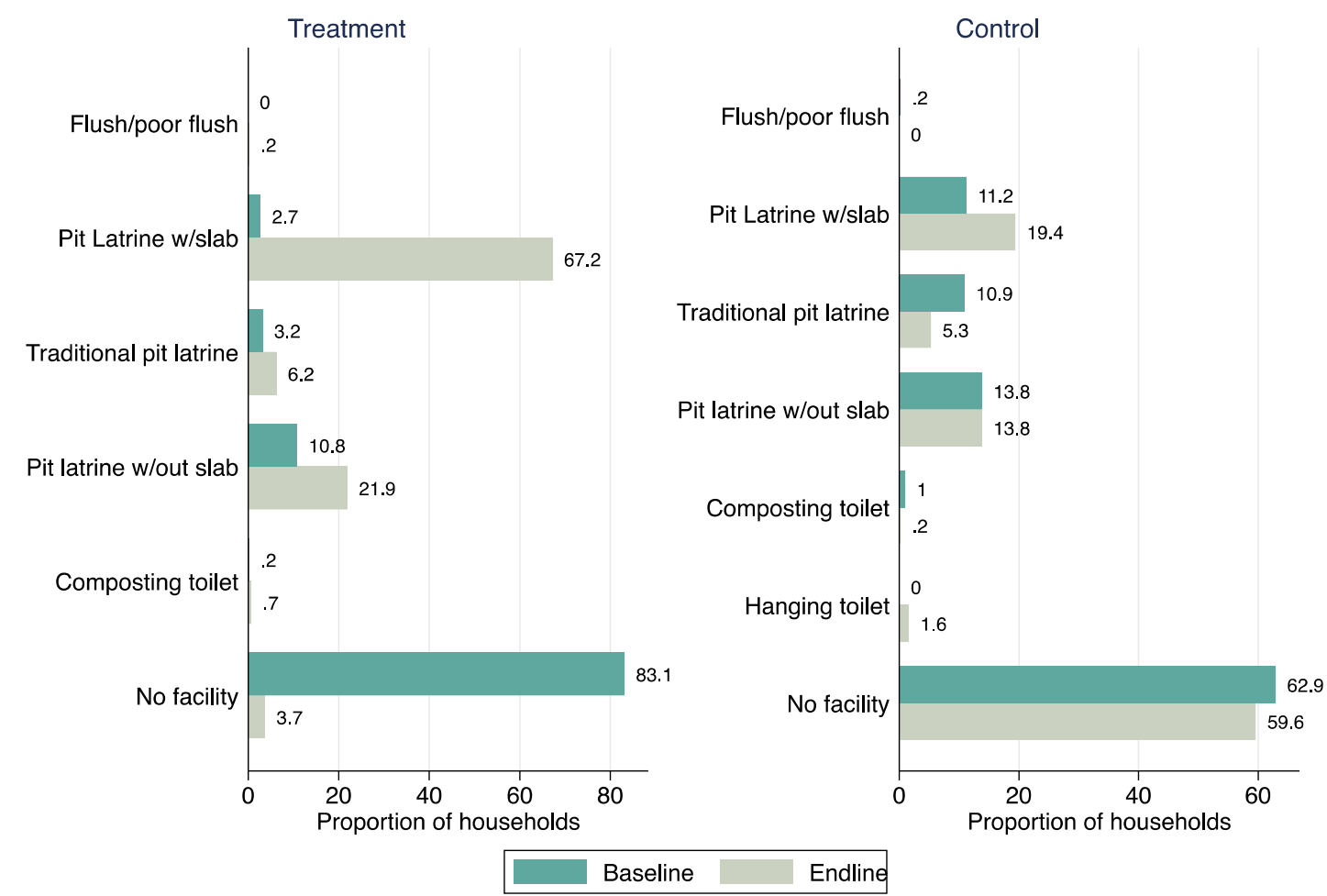

Source: Authors' own

\section{Table 5.1 Descriptive statistics about use of improved toilet facilities at baseline}

\begin{tabular}{|l|l|l|l|l|l|}
\hline & Baseline & Endline & Diff & t-stat & p-value \\
\hline Treatment group & $\begin{array}{l}0.06 \\
(0.00)\end{array}$ & $\begin{array}{l}0.74 \\
(0.01)\end{array}$ & -0.68 & -32.15 & $0.00^{\text {*** }}$ \\
\hline Control group & $\begin{array}{l}0.23 \\
(0.01)\end{array}$ & $\begin{array}{l}0.25 \\
(0.01)\end{array}$ & -0.02 & -0.67 & 0.50 \\
& & & \\
\hline
\end{tabular}

Note: Standard errors in parentheses. ${ }^{* * *} p<0.01,{ }^{* *} p<0.05,{ }^{*} p<0.1$.

Source: Authors' own. 
In Table 5.2, we provide impact estimates based on four models to capture the effect of the programme on the use of sanitation facilities. Models in columns 2, 3 and 4 control for household characteristics. Our preferred estimates in column 4 suggest a positive impact of the CLM programme on sanitation facilities. This estimation is consistent across different specifications.

\section{Table 5.2 Programme impact on use of improved toilet facilities}

\begin{tabular}{|c|c|c|c|c|}
\hline & $\begin{array}{l}\text { DiD } \\
\text { (Naïve) } \\
\text { (1) }\end{array}$ & $\begin{array}{l}\text { DiD } \\
\text { (Controls) } \\
()\end{array}$ & $\begin{array}{l}\text { DiD (PS } \\
\text { weighted) } \\
\text { (3) }\end{array}$ & $\begin{array}{l}\text { DiD (PS } \\
\text { common } \\
\text { support) } \\
\text { (4) }\end{array}$ \\
\hline CLM programme & $\begin{array}{l}0.668^{\star \star \star} \\
(0.017)\end{array}$ & $\begin{array}{l}0.661^{\star \star *} \\
(0.015)\end{array}$ & $\begin{array}{l}0.653^{* * *} \\
(0.017)\end{array}$ & $\begin{array}{l}0.661^{\star * *} \\
(0.015)\end{array}$ \\
\hline \multicolumn{5}{|l|}{ Household characteristics } \\
\hline Proportion of ill members & & $\begin{array}{l}-0.049 \\
(0.042)\end{array}$ & $\begin{array}{l}-0.059 \\
(0.042)\end{array}$ & $\begin{array}{l}-0.062 \\
(0.044)\end{array}$ \\
\hline Members under 15 and over 60 & & $\begin{array}{l}0.022 \\
(0.056)\end{array}$ & $\begin{array}{l}0.010 \\
(0.051)\end{array}$ & $\begin{array}{l}0.025 \\
(0.057)\end{array}$ \\
\hline Both parents present & & $\begin{array}{l}-0.139 \\
(0.073)\end{array}$ & $\begin{array}{l}-0.137 \\
(0.080)\end{array}$ & $\begin{array}{l}-0.148 \\
(0.072)\end{array}$ \\
\hline Proportion of children (aged $0-5$ ) & & $\begin{array}{l}0.023 \\
(0.018)\end{array}$ & $\begin{array}{l}0.102^{*} \\
(0.038)\end{array}$ & $\begin{array}{l}0.059 \\
(0.034)\end{array}$ \\
\hline Proportion of girls (aged 6-17) & & $\begin{array}{l}-0.017 \\
(0.150)\end{array}$ & $\begin{array}{l}0.024 \\
(0.136)\end{array}$ & $\begin{array}{l}-0.019 \\
(0.158)\end{array}$ \\
\hline Constant & $\begin{array}{l}0.149^{* \star \star} \\
(0.004)\end{array}$ & $\begin{array}{l}0.264 \\
(0.128)\end{array}$ & $\begin{array}{l}0.222 \\
(0.123)\end{array}$ & $\begin{array}{l}0.259 \\
(0.136)\end{array}$ \\
\hline Observations & 2,336 & 2,336 & 2,320 & 2,216 \\
\hline R-squared & 0.506 & 0.513 & 0.518 & 0.525 \\
\hline Number of households & 1,168 & 1,168 & 1,160 & 1,108 \\
\hline
\end{tabular}

Note: Robust standard errors in parentheses ${ }^{* \star *} p<0.01,{ }^{* *} p<0.05,{ }^{*} p<0.1$; DiD: difference-in-differences. Source: Authors' own.

Looking at access to toilet facilities based on households' wealth index score, we observe that at baseline, households in the poorest quintile were less likely to use improved toilet facilities (2.3 per cent) than those in the wealthiest quintile (18.5 percent). Changes over time were also biggest within the poorest quintile, with 75.4 per cent of households having access to improved toilet facilities at endline (compared to 69.6 per cent for the richest quintile). 
Comprehensive Social Protection Programming: What is the Potential for Improving Sanitation Outcomes?

We also consider the use of improved sources of drinking water for treatment and control groups. When looking at differences between baseline and endline (Table 5.3), there is no significant difference between baseline and endline for either group. In other words, sources of drinking water have remained unchanged from baseline to endline. Only slightly more than one in four CLM participants consumed water from improved sources, and this remained the same between baseline and endline. It is notable that households in the control group are roughly twice as likely to use improved water sources, and that this proportion remained roughly the same between baseline and endline.

\section{Table 5.3 Descriptive statistics about use of improved sources of drinking water at baseline}

\begin{tabular}{|l|l|l|l|l|l|}
\hline & Baseline & Endline & Diff & t-stat & p-value \\
\hline Treatment group & 0.26 & 0.26 & 0.00 & 0.07 & 0.95 \\
\hline & $(0.02)$ & $(0.02)$ & & & \\
\hline Control group & 0.48 & 0.48 & 0.00 & 0.11 & 0.91 \\
\hline & $(0.02)$ & $(0.02)$ & & & \\
\hline
\end{tabular}

Note: Standard errors in parentheses. ${ }^{* * *} p<0.01,{ }^{* *} p<0.05,{ }^{*} p<0.1$. Source: Authors' own.

When we explore the type of sources of drinking water (Figure 5.2), we observe some differences between CLM participants and the control group. Spring water is the most common source of drinking water for both groups, although a higher proportion of CLM programme participants rely on this source, around 70 per cent, compared to 50 per cent in the control group. The use of standpipes and private faucets appears to be more prevalent among non-participants, around half of households in the control group rely on those facilities to obtain drinking water whereas only 25 per cent of CLM participants make use of this type of facilities. There do not seem to be important shifts on the use of sources of drinking water from baseline to endline in either of the groups. 


\section{Figure 5.2 Types of sources of drinking water used by treatment and control groups at baseline and endline}
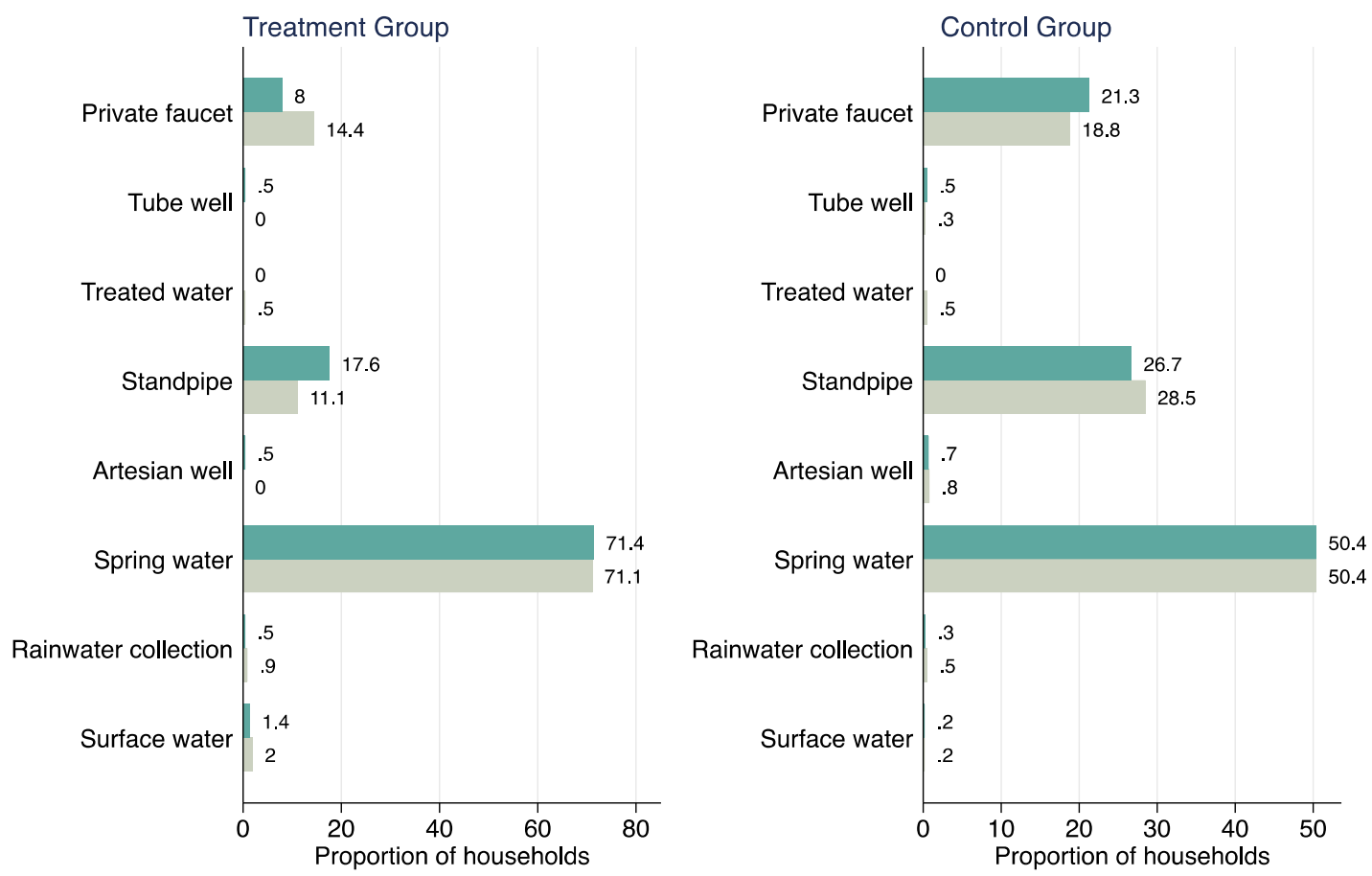

Baseline Endline

Source: Authors' own.

Estimations in Table 5.4 suggest that the programme did not have a significant effect on use of improved sources of water, even after including household-level controls. Households in the poorest quintile were least likely to have access to safe drinking water (14 per cent), compared to the richest quintile (44.6 per cent). We observe some increase in access to safe drinking water for the poorest quintile at endline (24.6 per cent) but no notable change for the richest quintile (46.1 per cent). 


\section{Table 5.4 Programme impact on use of improved sources of drinking water}

\begin{tabular}{|c|c|c|c|c|}
\hline & $\begin{array}{l}\text { DiD } \\
\text { (Naïve) } \\
(1)\end{array}$ & $\begin{array}{l}\text { DiD } \\
\text { (Controls) } \\
(2) \\
\end{array}$ & $\begin{array}{l}\text { DiD (PS } \\
\text { weighted) } \\
\text { (3) }\end{array}$ & $\begin{array}{l}\text { DiD (PS } \\
\text { common } \\
\text { support) } \\
\text { (4) }\end{array}$ \\
\hline CLM programme & $\begin{array}{l}-0.000 \\
(0.016)\end{array}$ & $\begin{array}{l}-0.003 \\
(0.016)\end{array}$ & $\begin{array}{l}-0.004 \\
(0.020)\end{array}$ & $\begin{array}{l}-0.003 \\
(0.015)\end{array}$ \\
\hline \multicolumn{5}{|l|}{ Household characteristics } \\
\hline Proportion of ill members & & $\begin{array}{l}-0.010 \\
(0.005)\end{array}$ & $\begin{array}{l}-0.015 \\
(0.007)\end{array}$ & $\begin{array}{l}-0.010 \\
(0.005)\end{array}$ \\
\hline Members under 15 and over 60 & & $\begin{array}{l}0.001 \\
(0.009)\end{array}$ & $\begin{array}{l}-0.004 \\
(0.011)\end{array}$ & $\begin{array}{l}-0.006 \\
(0.011)\end{array}$ \\
\hline Both parents present & & $\begin{array}{l}0.017 \\
(0.009)\end{array}$ & $\begin{array}{l}0.019 \\
(0.014)\end{array}$ & $\begin{array}{l}0.011 \\
(0.012)\end{array}$ \\
\hline Proportion of children (aged $0-5$ ) & & $\begin{array}{l}-0.019 \\
(0.035)\end{array}$ & $\begin{array}{l}-0.014 \\
(0.049)\end{array}$ & $\begin{array}{l}-0.024 \\
(0.042)\end{array}$ \\
\hline Proportion of girls (aged 6-17) & & $\begin{array}{l}-0.012 \\
(0.014)\end{array}$ & $\begin{array}{l}-0.025 \\
(0.016)\end{array}$ & $\begin{array}{l}-0.021 \\
(0.018)\end{array}$ \\
\hline Constant & $\begin{array}{l}0.982^{\star * *} \\
(0.004)\end{array}$ & $\begin{array}{l}0.986^{\star * *} \\
(0.012)\end{array}$ & $\begin{array}{l}0.990^{* * *} \\
(0.027)\end{array}$ & $\begin{array}{l}0.996^{\star * *} \\
(0.022)\end{array}$ \\
\hline Observations & 2,336 & 2,336 & 2,320 & 2,216 \\
\hline R-squared & 0.000 & 0.003 & 0.004 & 0.003 \\
\hline Number of households & 1,168 & 1,168 & 1,160 & 1,108 \\
\hline
\end{tabular}

Note: Robust standard errors in parentheses ${ }^{* *} p<0.01,{ }^{* *} p<0.05,{ }^{*} p<0.1$; DiD: difference-in-differences. Source: Authors' own.

As we will see in the qualitative findings below, the fact that there was no change in the source of drinking water does not mean that there was no change in the quality of water consumed by CLM participants and their families. The question about sources of drinking water did not allow for discerning any changes in treatment of water before usage, such as using a water filter for purification.

\subsection{Qualitative findings}

In this section we explore CLM participants' and programme staff perceptions about impacts of the CLM programme on sanitation and health, pathways to impact and challenges to achieving impact. Discussions and interviews were held with women and men separately and we comment on differences by gender if and where relevant. 
Comprehensive Social Protection Programming: What is the Potential for Improving Sanitation Outcomes?

\subsubsection{Perceived programme effects}

Qualitative findings about programme impacts on toilet facilities mirror quantitative estimates. Almost all respondents conveyed the importance of using latrines, speaking about the risk of disease when defecating in the open and noting their change in sanitation behaviour since participating in the CLM programme.

We used to poop on the ground, and we could get sick more easily, for example flies used to go on our poop and then get in our food, this can give you cholera. Now that CLM has given us toilets we are less likely to be ill. (MBFGCLM2-2-female)

The latrine is important. If you go to the toilet in the woods, it can infect the water. It can give you cholera and you can catch germs. (LCFGCLM2-2-female)

When they [children] poop on the ground, the microbes can enter the children's parts, and then the flies and the wind can take the microbes and bring them to the food. This is why children have major diseases such as fever, typhus and cholera... The toilet is important because the children go there often, the plants don't hurt them anymore, the thorns don't sting them anymore, when they need them, they have a place to go, you are not afraid for the children because you know they have a place to go, when it rains they can do their needs without problems. They have no problems when it rains. (MKFGCLM5-2-female)

Positive comments were made by women and men, and we are unable to discern from the data whether there were substantial gender differences in sanitation behaviour prior to the programme or as a result of participation in the intervention.

The fact that the CLM programme provided materials to all its participants for building their latrines played a strong role in ensuring that behaviour change took place. Some participants found it easier than others to solicit support from spouses, family, or community members to help build their latrines, sometimes leading to delays in their establishment. CLM case managers actively encourage participants to make this a priority and would follow up during their regular home visits.

Qualitative data also confirms quantitative findings about sources of drinking water. The majority of respondents indicated using the same water source all year round. Those using spring or river water would report seasonal changes, 
requiring them go elsewhere to fetch water. In the remote areas of Mable, for example, respondents indicated that they are able to use local springs or streams in the rainy season but that they have to go to the Manga river in the dry season. Users of public standpipes, especially in the less remote area of La Chappelle, reported that these would sometimes be out of service, but they were generally deemed reliable.

Despite the lack of change in the source of drinking water, qualitative findings suggest a considerable shift towards treating water before consumption. As noted above, CLM participants received a water filter at the start of the programme and received repeated messages about how to use it and the importance of doing so. The provision of the water filter emerged as one of the key benefits of the programme. In an FGD, women participating in the CLM programme talked about why they considered the provision of the water filter so important (MBFGCLM2-2-female):

Respondent 3: My child had diarrhoea, since I have the filter he drinks the treated water and doesn't have diarrhoea anymore.

Respondent 8: When you gave untreated water to the child, they would get microbes from the water, since l've been giving them the treated water they are no longer sick.

Respondent 1: Since l've been giving treated water to my son he doesn't get any disease, I don't spend money for the hospital.

Respondent 2: When you wash your child with treated water he doesn't get infections.

In addition to material support provided by the CLM programme to directly facilitate sanitation practices, respondents also highlighted the advice they received and how this helped them to gain helpful knowledge. When asked whether the support by CLM case managers was useful, one female respondent noted: 'Yes, they told me to have the child wash his hands when he comes from using the latrine, don't let him walk around barefoot' (MKCSCLM5-2-female).

In response to questions about how the programme changed their children's lives, almost all respondents spoke about how they benefited from messaging and advice and how this led to a change in sanitation practices:

The children have changed thanks to the programme. They have shown me how to take care of them - not to let them go around dirty. I always bathe them and give them treated water... They aren't the same as they used to be. They are cleaner.

(LCCSCLM2-1-female) 
Female participants also reported having changed their practices in handling children's faeces and keeping themselves and their children clean. In line with advice received through the programme, they would dispose of faeces in the newly built pit latrine, wash their children's bottom and wash their own hands with soap after handling faeces and cleaning their children.

In addition to these self-reported changes in behaviour, fieldworkers also observed that houses and newly built pit latrines were kept clean and were wellmaintained. They also noted that most participants were using the water filters at the time of their visits and that soap was available for washing hands.

Qualitative findings thus point to the combined effect of different types of support provided by the CLM programme. The provision of materials to build a latrine and messaging regarding the importance of constructing a latrine, directly contributed to improved sanitation practices. With respect to treatment of water prior to its consumption, the combination of repeated messaging in conjunction with the provision of water filters as well as demonstrations about and monitoring the use of water filters led to a synergetic effect.

Overall, respondents spoke highly of the programme and the changes it caused:

Because of CLM, the children drink treated water, the children are not sick and they don't walk around dirty. CLM taught me how to keep them clean. The children don't get wet in the rain; they have a house to sleep in. (LCCSCLM2-4-female)

\subsubsection{Challenges to impact}

Despite direct provision of cash transfers and improved income-generating opportunities as a result of the programme, financial constraints still impeded the ability to adhere to advice about sanitary practices. One respondent reflected on lack of money preventing them from always using soap when washing hands: 'I always wash my hands with soap. Not every time, because you don't have the means' (LCCSSpouse2-2). During an FGD, one participant noted that diapers are only used occasionally given their cost.

Once the child is three months old, we don't use diapers; we put him/her in underwear and shorts. We put them in diapers when we are going out with them, but we don't buy them often because we don't have the money.

(LCFGSpouse2-2-male)

The use of diapers or nappies varied among CLM participants, not necessarily always leading to hygienic or desirable practices. Some respondents indicated that their babies always wore a nappy or diaper to prevent them getting dirty and defecating in the open. However, the most common response was that children 
Comprehensive Social Protection Programming: What is the Potential for Improving Sanitation Outcomes?

would often be without a nappy, diaper, or clothing when at home, but that they would wear such items when going out or being left with others. The main reason for infants not wearing diapers was their cost, which proved prohibitive. An important impediment to wearing nappies or clothes was the amount of time and effort required to properly wash them.

When using nappies, respondents indicated they would dispose of the faeces in the latrine to then wash and dry the cloth so it could be reused. However, in the case of diapers, disposal was arguably less hygienic and environmentally unfriendly. In the absence of any waste management, diapers would be thrown in the latrine or in water sources, such as rivers. In response to the question of what women did with their baby's poop, respondents said: 'If it's diapers, we throw them in the latrines. If it's clothes, we wash the clothes', while another respondent added: 'I throw it away in the river' (MKFGCLM2-2-female).

Ensuring that all family members, and especially children, adhere to sanitary practices also emerged as a challenge. Female respondents reflected on the difficulty to monitor their children's behaviour, and to ensure that they kept clean or wash their hands with soap. Male respondents also commented on this issue: 'When I leave the latrine, I always wash my hands with soap. On the other hand, when the child washes his hands by himself, he would wash it without soap' (MKCSSpouse2-4-male).

A recurrent issue among CLM participants - most of whom are women with young infants - is the struggle to combine many demands on their time, and juggling paid, unpaid, and care work responsibilities. As the programme incentivises productive activities that may require going to the market, working on the farm, or undertaking other tasks that are difficult to combine with childcare, women are often required to leave their children in the care of others. Depending on the strength of family and social networks, such care may be provided by family members, neighbours, or older siblings. Female respondents raised concerns about how well their children would be looked after when in the care of others, such as whether they would be well fed or kept clean. One respondent reflected: 'I spend less time with the baby. Sometimes I find she is soiled, because when I go to wash in the river, I leave her with the neighbour to watch over for me' (LCCSCLM2-3-female).

There are also questions about longevity of behaviour change and sustainability of impact after programme end. A few respondents indicated that they followed case managers' advice in part because they knew they would be monitored and wanted to prevent getting caught out. 
Yes - it has led me to change my behaviour. I do everything he tells me to do. For example, keeping the children clean. He tells me I should keep my house clean too. If I didn't listen to him, I would have been embarrassed when you came to visit today. (LCCSCLM2-3-female)

Finally, qualitative data also point to supply-side issues that undermine the ability to shift to use of improved sources of drinking water. Across the research sites, there are several sources of fresh water in the study sites with varying quality and difficulty in accessibility. This also explains the lack of programme impact on use of improved sources for drinking water.

In Mache Kana, there are several springs, creeks, and a river. People tend to use the river for bathing and laundry, and to use a spring for collecting drinking water. However, springs are not protected and when it rains, the overflow from the river contaminates the spring water, which makes it unsafe for consumption (MKCSCLM2-2). The quality of water from the river is also questionable as 'animals might defecate in it, and it's next to a creek and [some people] might drop bad things in it' (MKCSSPOUSE2-3-male).

In comparison, in La Chappelle, there are standpipes that provide clean water throughout the year. However, the number of standpipes is too low to cover the population adequately, and some CLM members living in this zone used spring water for drinking instead (LCFGCLM5-2). These standpipes are considered important assets to the community: 'The standpipe, because that's where I get water to drink, to wash in and to wash the clothes. I get water every day' (LCCSCLM2-2-female).

For residents in Mable, which is the most remote of the three sites, water access is very limited. People collect rainwater. If this is insufficient, they rely on a pond. Once the pond dries up, then they go to the nearest water source or the river in the valley that could take at least 40 minutes to reach (MBFGCLM5-2-female). The elevation and gradient of the route make the task nearly impossible without the help of a draught animal such as donkey, mule, or horse. None of the CLM members owned draught animals so they would often have to borrow them from other neighbours. 


\section{Conclusion and implications for policy}

This paper sought to assess whether a comprehensive social protection intervention can promote access to and use of improved sanitation services and water sources, thereby seeking to promote cross-sectoral learning and collaboration between WASH and social protection sectors.

\subsection{Overview of empirical findings}

Findings suggest that a comprehensive intervention such as the CLM programme in Haiti has potential to improve access to sanitation facilities and change sanitation practices. Programme participation increases access to improved toilet facilities, in large part because materials to build latrines are provided through the programme. Qualitative data suggests that these new facilities are also used by all members of the household.

These findings do warrant caution. In the absence of evaluation data beyond the end of the programme and in recognition of evidence suggesting that the construction of sanitation facilities may not lead to lasting impact on sanitation behaviours (Hirai et al. 2016), we are unable to draw conclusions about the sustainability of impacts. Access to and use of improved toilet facilities may be relatively short-lived. In addition, qualitative data about the use of pit latrines for disposing of diapers or other rubbish raises concerns about sustainability from an environmental perspective. Moreover, as the data does not hold detailed information about individual behaviour, we are unable to ascertain whether impact was greater on women versus men or across the age distribution. It should also be noted that because of lack of data on faecal disposal management, this study does not allow for drawing conclusions about safely managed sanitation. Finally, we are unable to draw conclusions about any impact on the wider community: control group households in the quantitative sample did not live in the same communities and the qualitative sample did not include non-programme participants. Evidence from other comprehensive interventions similar to the CLM programme - such as in Burundi - do suggest substantial intra-community spillover effects in relation to sanitation and health practices (Roelen and Devereux 2019).

The programme does not significantly change access to or use of sources of drinking water. Quantitative data show that spring water remains the main source of drinking water, followed by public standpipes and private faucets. Qualitative data reveal that supply-side constraints hamper the ability to diversify to other sources of drinking water. As in other low-income countries, limited connectivity 
Comprehensive Social Protection Programming: What is the Potential for Improving Sanitation Outcomes?

to network services and poor quality of such services will continue to hamper access to improved sources of drinking water (Cook et al. 2020).

These findings do not mean that the programme does not lead to improved quality of the water consumed by its participants. The programme encourages treating water using a water filter before its use for drinking or cooking, and this practice appears to have been taken on by most CLM participants. The programme's bundled approach of providing the filter, repeated messaging about its use and checks on its use during home visits explain the widespread reported usage of such filters. Again, long-term effects of the programme on treating drinking water before its use cannot be concluded from this study.

\subsection{Contributions to literature}

Findings in this paper mirror and add to existing WASH literature in various ways.

First, bundled interventions can be effective. Qualitative findings clearly pointed to how the direct provision of materials to build pit latrines coupled with repeated messaging and follow-up results in better awareness and behaviour change. Respondents and their families acknowledge the importance of using latrines to prevent illness and spreading disease. They widely report using their latrines for defecation and disposing of children's faeces. Similarly, the combination of advice, follow-up, and economic support facilitated hygiene practices such as washing hands with soap and children wearing nappies. These self-reported changes in behaviour were corroborated by observational data, indicating that latrines and handwashing facilities were in place. These findings mirror evidence from within the sanitation literature suggesting that behaviour change interventions can be more effective when coupled with financial incentives such as targeted subsidies. The role of case managers is crucial in this respect, with mutual trust and respect likely to enhance short-term impact. Their engagement also allows for more tailored responses to households' particular circumstances, potentially leading to more sustained impact. Lessons from the sanitation literature (including CLTS) suggest that impacts could be bolstered by enhancing the intervention's bottom-up nature.

Second, this study's findings also resonate with literature within the sanitation domain on how women's empowerment can improve sanitation and hygiene practices. The CLM programme explicitly targets women in acknowledgment of their vulnerable position in society and with the aim to foster economic empowerment. Wider evaluation findings indicate that the programme leads to women being more economically active and becoming more autonomous (Roelen et al. 2019). Although not explicitly mentioned in the data, women's strengthened positions may have played into improved practices, especially in relation to children. 
At the same time, this study also points to a concern that has been raised by feminist economists and other scholars in relation to a wide range of interventions that aim to improve children's and families' lives: making women the focal point for interventions to leverage their position as primary caregivers means that schemes can inadvertently worsen women's outcomes as well as hamper programme effects for their children and families. Findings indicate how women struggle to combine their many responsibilities, especially in undertaking paid work and unpaid care. In terms of sanitation and hygiene practices, women reported difficulties in maintaining good practices especially when having to leave children in the care of others.

This paper also points to the importance of context. The literature review shows that many learnings about financial incentives in the WASH sector originate from urban contexts where access to sanitation and water services is often more expensive and their costs prohibit many people from uptake. Experiences with the CLM programme in Haiti show that economic support and in-kind provision of materials can also lift constraints in a rural context. At the same time, findings with respect to access to drinking water show that the degree of remoteness and availability of public services serve as binding constraints beyond the reach of household-focused interventions. In the context of Haiti, such constraints exist against a backdrop of limited government capacity and continued political instability, suggesting that improvements in public services are unlikely to occur in the near future.

\subsection{Implications for policy}

Findings point to the potential and need for stronger cross-sectoral linkages between WASH and social protection. Both sectors have widespread experience with the implementation of financial incentives in the form of targeted subsidies and cash transfers respectively. Emerging evidence in both sectors points to the potential of bundled interventions combining behaviour change components with economic support. However, policy coordination or even lesson-learning across sectors appears limited, even though implementation issues such as targeting cut across WASH and social protection.

These findings translate into various policy recommendations:

\subsubsection{Implement context-appropriate combination of interventions}

Complementing financial support with in-kind services and behaviour change interventions can improve sanitation practices more than any standalone intervention. The optimal package will depend on context and should be adjusted accordingly. Positive experiences make it appealing to supplant interventions from urban areas into rural contexts and vice versa, or to implement schemes 
Comprehensive Social Protection Programming: What is the Potential for Improving Sanitation Outcomes?

that were piloted in areas with better access to public services in communities with limited-service provision. New interventions should draw on past experiences elsewhere, yet their scope should be appropriately adjusted to the population it serves.

\subsubsection{Pay closer attention to women's roles}

Focusing policy efforts on women can lead to greater impacts on sanitation practices. Strengthening women's decision-making power increases their influence over household decisions. At the same time, reinforcing their roles as primary caregivers can lead to increased drudgery, reinforce the double burden of paid and unpaid work, and ultimately perpetuate gender inequality. Design of WASH interventions could learn from experiences with so-called 'gendersensitive' social protection that makes explicit the ways in which interventions take account of women's roles and can counteract forms of gender inequality.

\subsubsection{Build and strengthen cross-sectoral linkages}

Interventions in both sectors - notably those that combine financial incentives with behaviour change programmes - hold considerable overlap in terms of foreseen outcomes and target groups. Cross-sectoral learning and coordination can make programmes more effective and efficient. More specifically, this could take place in the following areas:

- Targeting: Deciding who should participate in programming is a perennial and intractable challenge for both the WASH and social protection sectors. Within social protection, the case for targeting is made on ideological and pragmatic grounds: redirecting resources from the wealthy to those who are in need underpins redistributive justice, while budget constraints mean that only a segment of the population can be included in programming (Devereux 2016). However, proponents argue that any form of targeting creates a divide between the 'deserving' and 'non-deserving', is based on an arbitrary poverty line or alike, and ultimately creates social tension (ibid.). An implicit yet fundamental factor underpinning this debate is that social protection is focused on making change happen at the household or individual level. Wider community impacts are often labelled as unintended side or spillover effects, without much consideration of the potential benefits of such impacts. There is an opportunity for social protection - and especially those in 'cash plus' programming - to learn from experiences in WASH about the respective benefits and challenges of aiming for community-level change.

- Identification: Even if the need for targeting is agreed, deciding on the mechanisms for identifying who should receive support is highly contentious. Perfect targeting does not exist, and all mechanisms - from means-testing to 
community-based targeting - come with errors and costs (Devereux et al. 2017). There is no 'best' mechanism, with the appropriate balance between accuracy and cost-benefit often depending on context and how well targeting mechanisms are designed and implemented (ibid.). Given the broad range of experiences within the social protection sector, there is scope for WASH to learn from the social protection field about options for identification of households or individuals eligible for support.

- Behaviour change: The WASH sector has widespread experience in models of behaviour change that combine individual and community-based actions and outcomes. The rapid rise of the social protection sector in many countries in the last decades means there is a good basis for delivering economic support. Instead of trying to reinvent the wheel within WASH interventions that combine behaviour change with financial incentives or social protection 'cash plus' schemes that layer behaviour change components on to cash transfers, it may be more effective and efficient to collaborate and build crosssectoral schemes.

- Needs assessment and monitoring: Social protection interventions including 'cash plus' - would benefit if situation analyses and needs assessments underpinning programme design pay closer attention to WASH and consider how they might have an effect in this area. The same holds for monitoring and evaluation (M\&E) of interventions. As most 'cash plus' interventions only pay cursory attention to the issue of WASH, most M\&E frameworks only include limited focus on WASH - as indeed was the case for this study. In addition to asking about access to and use of sanitation facilities and sources of drinking water, questions about maintenance and waste management are important to understand whether 'cash plus' programmes can achieve safe sanitation in a sustainable manner. 


\section{Technical annexe}

This document provides further detail about the quantitative methods employed in this study.

In the absence of a random assignment of the treatment and comparison groups, the quantitative component of the evaluation is based on a quasiexperimental approach. The treatment group (CLM members) was predetermined by programming considerations, with all eligible women in the programme sites having been selected into the programme. Ethical considerations, potential spillover effects, and budget constraints precluded the possibility of establishing counterfactuals within the same communities or undertaking a cluster-randomised control trial. The control group was therefore sampled from other communities in the Central Plateau region by (i) selecting neighbourhoods similar to those where the programme took place ${ }^{2}$ and (ii) identifying women with similar living conditions as programme participants. Sampling procedures for the control group mirrored the targeting process for the CLM programme by employing social mapping and participatory wealth rankings.

Baseline data collection for programme participants occurred between June and July 2017; baseline data for the control group was collected from August to December 2017. Endline data for programme participants as collected almost two years after the start of the CLM programme in April 2019; endline data for the control was collected between May and June 2019. Both survey rounds included six modules: (i) household member information about education, health seeking behaviour, work (for those aged six years or older), child stimulation activities (for children aged 3-5); (ii) living conditions; (iii) food and diet; (iv) maternal stress and depression; (v) child protection attitudes; and (vi) balance between work and care. At baseline, the sample includes 631 programme participants and 750 control group members. At endline, data includes 561 programme participants and 607 control group members.

As the assignment of the CLM programme was not random but rather a predetermined process, a direct comparison between treated and untreated households may overlook systematic differences in each group and thus bias the results. The risk of bias is confirmed by findings in Table 4.1, pointing to significant differences between the treatment and control groups. We

2 Selection of neighbourhoods in the control group considered levels of accessibility and infrastructure similar to those where the programme was being implemented. For instance, Desarmes, which is within the reach of Mirebalais, was selected as a control neighbourhood as it shares the proximity of La Chapelle (treatment neighbourhood) to the main road westwards from Mirebalais. Similarly, the control area Savanette which is as remote as Mableux and Marche Kana (treatment neighbourhoods). 
Comprehensive Social Protection Programming: What is the Potential for Improving Sanitation Outcomes?

address this issue by employing a quasi-experimental approach, which involves a three-step econometric procedure (Angrist and Pischke 2008) that includes (i) constructing a valid counterfactual or comparison group,

(ii) matching CLM participants in the treatment group with non-participants in the comparison group, and (iii) estimating average treatment effects of the programme.

The first step of the process aims to construct a valid counterfactual or comparison group with similar characteristics to those participating in the programme. In this stage, we estimate the probability of participation for individuals in our sample based on observed characteristics at baseline. Characteristics include both individual attributes as well as characteristics of the household where the respondent lives. We use the location of the household, number of members in the household, the number of members over the age of ten who work, and a wealth index (a measure of the cumulative living standard of the household). We also use some other personal characteristics such as the age of the respondent, marital status of the respondent, and literacy of the respondent and their spouse (whether they know how to read and write). In this step, we obtain probabilities of participation or propensity scores for each respondent in our sample.

The second stage entails matching CLM programme participants (treatment group) with respondents in the control group (non-participants) based on the probability (also called the propensity score) obtained in the previous stage. This procedure is often performed using techniques such as the nearest neighbour matching that finds the closest observation based on the propensity score (Heckman, Lalonde and Smith 1999). We make use of the nearest neighbour algorithm without replacement, which means that individuals in the control group (non-CLM participants) were only matched once. For robustness check, we also use the coarsened exact matching algorithm, or CEM; this technique coarsens the data to find exact matches (individuals with the same characteristics and therefore equal probability of participation). We assess the quality of the matching following the standard test proposed by Rosenbaum and Rubin (1983). Results of balancing test show reductions in the bias after matching (see Table A1).

A valid counterfactual is achieved once characteristics of respondents in the treatment and control group are balanced and therefore there are no significant differences between them. In our case, after matching, we observe that characteristics are balanced in the treatment and control groups (see Table A1 and Figures A1 and A2). This also confirms the quality of the matching. Only after the propensity scores are estimated and characteristics of the treatment and comparison groups at baseline are balanced (i.e. baseline characteristics 
Comprehensive Social Protection Programming: What is the Potential for Improving Sanitation Outcomes?

are significantly equal between the groups), the effect of the programme is estimated.

The final stage of the process aims to estimate the average treatment effect of the programme on the treated (CLM participants) using the difference-indifferences (DiD) approach. This method compares changes in outcomes over time between individuals in the treatment group and the control group. We estimate the treatment effect following a standard econometric procedure that accounts for observable and unobservable time-invariant variables that may influence participation in the programme and the evaluated outcome. In this process we consider a set of covariates such as family structure characteristics (i.e. the proportion of female members in the household, the proportion of children under the age of five, etc.) that are likely to affect the outcome but have not been influenced by the programme. After applying this method, a more reliable estimate of the effect of the programme is obtained since it reflects the differences in outcomes between CLM participants and the control group that are strictly attributable to the programme (Gertler et al. 2016). 
Table A1 Balancing property of the covariates - sanitation facilities and sources of drinking water outcomes

\begin{tabular}{|c|c|c|c|c|c|c|c|c|}
\hline \multirow[b]{2}{*}{ Variable } & \multirow[b]{2}{*}{ Status } & \multicolumn{2}{|l|}{ Mean } & \multirow[b]{2}{*}{$\%$ Bias } & \multirow{2}{*}{$\%$ Reduction } & \multicolumn{3}{|l|}{ t-test } \\
\hline & & Treatment & Control & & & t- statistic & $p>|t|$ & \\
\hline \multirow{2}{*}{ Department where respondent lives } & Unmatched & 4.8628 & 5.1716 & -15.5 & & -2.63 & 0.009 & \\
\hline & Matched & 4.8628 & 5.0794 & -10.9 & 29.9 & -1.8 & 0.072 & \\
\hline \multirow{2}{*}{ Household size } & Unmatched & 10.143 & 11.952 & -24.6 & & -4.17 & 0.000 & \\
\hline & Matched & 10.143 & 11.282 & -15.5 & 37.1 & -2.66 & 0.008 & \\
\hline \multirow{4}{*}{$\begin{array}{l}\text { Household members aged ten or } \\
\text { older who work } \\
\text { Literacy of respondent (read and } \\
\text { write) }\end{array}$} & Unmatched & 1.4838 & 1.1881 & 23.8 & & 4.06 & 0.000 & \\
\hline & Matched & 1.4838 & 1.2527 & 18.6 & 21.8 & 3.08 & 0.002 & \\
\hline & Unmatched & 0.29242 & 0.4703 & -17.9 & & -3.02 & 0.003 & \\
\hline & Matched & 0.29242 & 0.38989 & -9.8 & 45.2 & -1.7 & 0.089 & \\
\hline \multirow{2}{*}{ Literacy of spouse } & Unmatched & 0.9639 & 0.9604 & 0.2 & & 0.04 & 0.969 & \\
\hline & Matched & 0.9639 & 0.94585 & 1.2 & -415.3 & 0.2 & 0.843 & \\
\hline \multirow{2}{*}{ Age of respondent } & Unmatched & 34.487 & 33.972 & 4.5 & & 0.77 & 0.444 & \\
\hline & Matched & 34.487 & 34.182 & 2.7 & 40.8 & 0.45 & 0.655 & \\
\hline \multirow{2}{*}{ Marital status of respondent } & Unmatched & 2.4657 & 2.3515 & 12.2 & & 2.08 & 0.038 & \\
\hline & Matched & 2.4657 & 2.4079 & 6.2 & 49.4 & 1.03 & 0.303 & \\
\hline \multirow{2}{*}{ Wealth index } & Unmatched & 2.5144 & 3.0891 & -41.2 & & -7.01 & 0.000 & \\
\hline & Matched & 2.5144 & 2.9314 & -29.9 & 27.4 & -5.06 & 0.000 & \\
\hline Sample & Pseudo R2 & LR chi2 & $p>c h i 2$ & Mean bias & Median bias & B & $\mathbf{R}$ & $\% \operatorname{Var}$ \\
\hline Unmatched & 0.053 & 85.18 & 0.000 & 17.5 & 16.7 & $55.4^{*}$ & 0.88 & 38 \\
\hline Matched & 0.030 & 45.89 & 0.000 & 11.8 & 10.3 & $41.2^{*}$ & 1.16 & 25 \\
\hline
\end{tabular}

Note: t-test of observed covariates before and after matching: nearest neighbour matching 
Figure A1 Test of common support: nearest neighbour matching

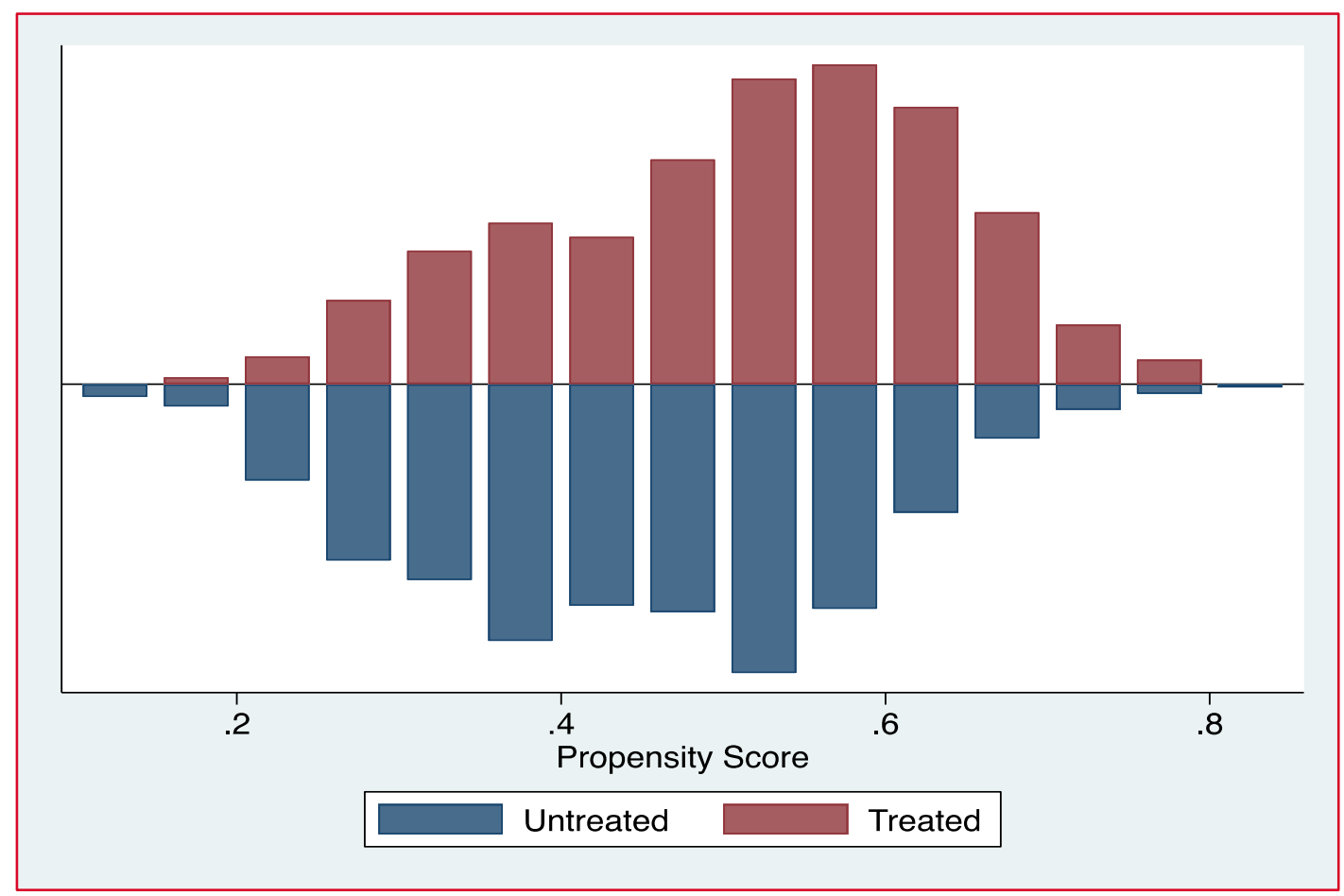

Figure A2 Density of propensity score matching of treated and control groups

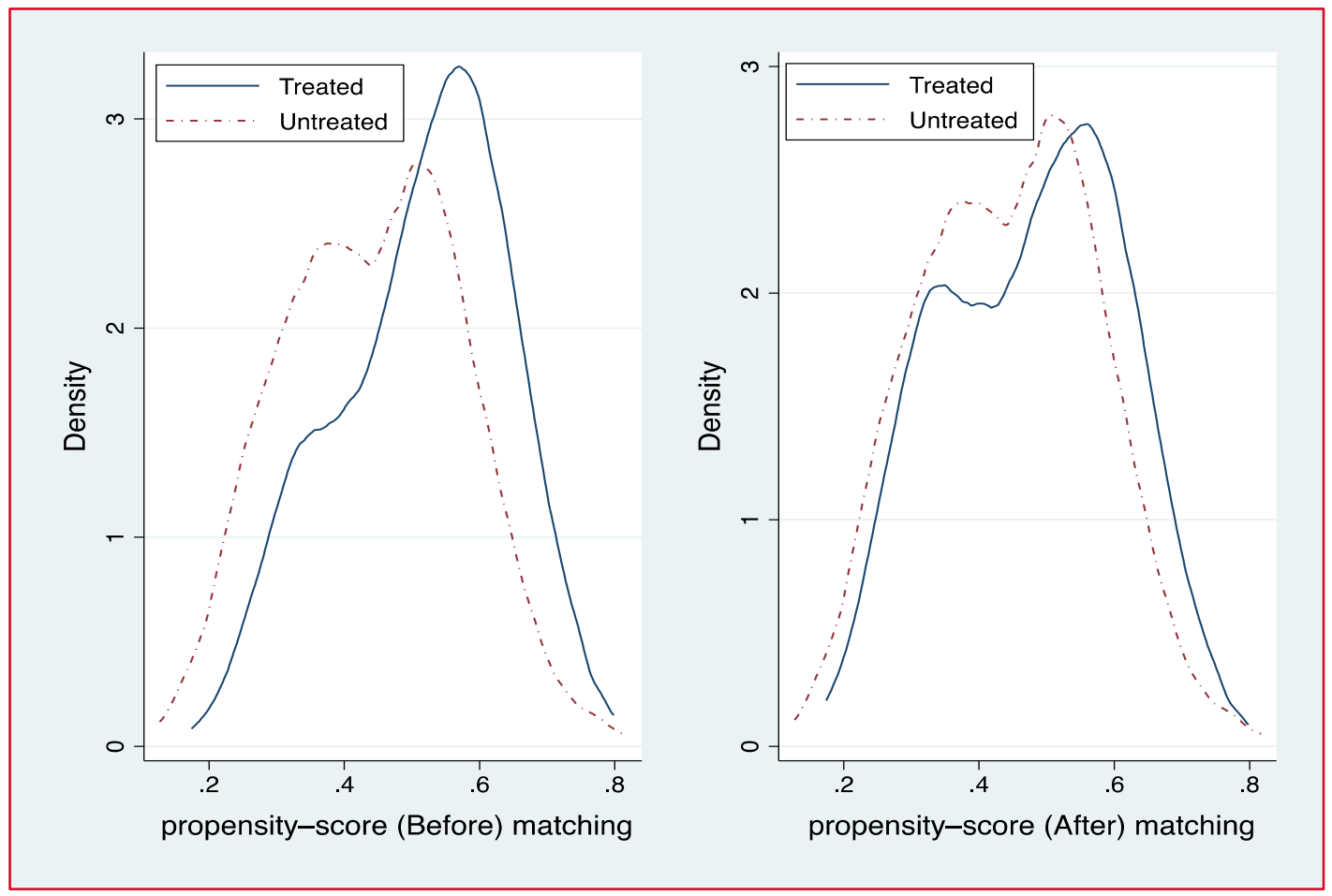




\section{References}

Andres, L.A. et al. (2019) Doing More with Less: Smarter Subsidies for Water Supply and Sanitation, Washington DC: World Bank

Angrist, J.D. and Pischke, J.S. (2008) Mostly Harmless Econometrics: An Empiricist's Companion, Princeton NJ: Princeton University Press

Banerjee, A. et al. (2015) 'A Multifaceted Program Causes Lasting Progress for the Very Poor: Evidence from Six Countries', Science 348.6236

Bastagli, F. et al. (2019) 'The Impact of Cash Transfers: A Review of the Evidence from Low- and MiddleIncome Countries', Journal of Social Policy 48.3: 569-94

Batmunkh, O.; Chase, C.; Galing, E. and Phuong La, M. (2019) Philippines: Can Subsidized Microloans Increase Toilet Ownership and Use for Poor Households?, From Evidence to Policy, Washington DC: World Bank

Buller, A.M.; Hidrobo, M.; Peterman, A. and Heise, L. (2016) 'The Way to a Man's Heart is through His Stomach?: A Mixed Methods Study on Causal Mechanisms through which Cash and In-Kind Food Transfers Decreased Intimate Partner Violence', BMC Public Health 16.488: 1-13

Cameron, L.; Santos, P.; Thomas, M. and Albert, J. (2021) 'Sanitation, Financial Incentives and Health Spillovers: A Cluster Randomised Trial', Journal of Health Economics 77: 102456

Chopra, D. and Zambelli, E. (2017) No Time to Rest: Women's Lived Experiences of Balancing Paid Work and Unpaid Care Work, Brighton: Institute of Development Studies (accessed 19 January 2022)

Cianelli, R. et al. (2014) 'Maternal - Child Health Needs Assessment in Haiti', International Journal of Applied Science and Technology 4.5: 30-38

CLTS Knowledge Hub (2016) Philippines (accessed 23 September 2021)

Cook, J.; Fuente, D.; Matichich, M. and Whittington, D. (2020) 'A Global Assessment of Nontariff Customer Assistance Programs in Water Supply and Sanitation', in Z. Chen, W.M. Bowen and D. Whittington (eds), Development Studies in Regional Science, Singapore: Springer

Cookson, T.P. (2018) Unjust Conditions: Women's Work and the Hidden Costs of Cash Transfer Programs, Oakland CA: University of California Press

de Groot, R.; Palermo, T.; Handa, S.; Ragno, L.P. and Peterman, A. (2017) 'Cash Transfers and Child Nutrition: Pathways and Impacts', Development Policy Review 35.5: 621-43

de Haan, A.; Dowie, G. and Mariara, J. (2020) 'To RCT or Not, is Not the Question: Methods for PolicyRelevant Research on Gender Equality', World Development 127: 104794

Devereux, S. (2016) 'Is Targeting Ethical?', Global Social Policy 16.2: 166-81

Devereux, S.; Roelen, K. and Ulrichs, M. (2016) 'Where Next for Social Protection?', IDS Bulletin 47.4: 103-18, DOI: 10.19088/1968-2016.158 (accessed 19 January 2022)

Devereux, S. et al. (2017) 'The Targeting Effectiveness of Social Transfers', Journal of Development Effectiveness 9.2: 162-211

Evans, B.; van der Voorden, C. and Peal, A. (2009) Public Funding for Sanitation - The Many Faces of Sanitation Subsidies, Geneva: Water Supply and Sanitation Collaborative Council

Field, E.M. and Maffioli, E.M. (2021) Are Behavioral Change Interventions Needed to Make Cash Transfer Programs Work for Children? Experimental Evidence from Myanmar, NBER Working Paper 28443, Cambridge MA: National Bureau of Economic Research

Gertler, P.J.; Martinez, S.; Premand, P.; Rawlings, L.B. and Vermeersch, C.M.J. (2016) Impact Evaluation in Practice, 2nd ed., Washington DC: World Bank

Greeley, M. (2019) Targeting the Ultra-Poor: Lessons from Fonkoze's Graduation Programme in Haiti, Learning Brief, Brighton: Institute of Development Studies (accessed 19 January 2022)

Guiteras, R.; Levinsohn, J. and Mobarak A.M. (2015) 'Encouraging Sanitation Investment in the Developing World: A Cluster-Randomized Trial', Science 348.6237: 903-6 

Sanitation Outcomes?

Hammer, J. and Spears, D. (2016) 'Village Sanitation and Children's Human Capital: Evidence from a Randomized Experiment by the Maharashtra Government', Journal of Health Economics 48: 135-48

Heckman, J.J.; Lalonde, R.J. and Smith, J.A. (1999) 'The Economics and Econometrics of Active Labour Market Programs', in O.C. Ashenfelter and D. Card (eds), Handbook of Labor Economics, Vol. 3, Part A, Amsterdam: North-Holland

Hirai, M.; Graham, J.P. and Sandberg, J. (2016) 'Understanding Women's Decision Making Power and its Link to Improved Household Sanitation: The Case of Kenya', Journal of Water, Sanitation and Hygiene for Development 6.1: 151-60

Holmes, R. and Jones, N. (2013) Gender and Social Protection in the Developing World: Beyond Mothers and Safety Nets, London: Zed Books

IHE and ICF (2018) Enquête Mortalité, Morbidité et Utilisation des Services en Haïti 2016-2017: Rapport de synthèse, Rockville MD: Institut Haïtien de l'Enfance (IHE) et ICF

IMF (2014) Haiti: Poverty Reduction Strategy Paper, Washington DC: International Monetary Fund Independent Expert Group of the Global Nutrition Report et al. (2020) 2020 Global Nutrition Report: Action on Equity to End Malnutrition, Bristol: Development Initiatives

JMP (2021) Updated Global Estimates for WASH in Households: Haiti Data, WHO/UNICEF Joint Monitoring Programme for Water Supply, Sanitation and Hygiene (accessed 13 July 2021)

Kohlitz, J.; Carrard, N. and Willetts, J. (2019) Support Mechanisms to Strengthen Equality and NonDiscrimination (EQND) in Rural Sanitation (Part 2 of 2), Frontiers of CLTS: Innovations and Insights 13 , Brighton: Institute of Development Studies

Komives, K.; Foster, V.; Halpern, J. and Wodon, Q. (2005) Water, Electricity, and the Poor: Who Benefits from Utility Subsidies?, Directions in Development, Washington DC: World Bank

Lantagne, D.; Balakrish Nair, G.; Lanata, C.F. and Cravioto, A. (2014) 'The Cholera Outbreak in Haiti: Where and How Did It Begin?', Current Topics in Microbiology and Immunology 2014.379: 145-64

Lennon, S. (2011) 'Fear and Anger: Perceptions of Risks Related to Sexual Violence against Women Linked to Water and Sanitation in Delhi, India', Briefing Note, Sanitation and Hygiene Applied Research for Equity and WaterAid

Lipscomb, M. and Schechter, L. (2018) 'Subsidies Versus Mental Accounting Nudges: Harnessing Mobile Payment Systems to Improve Sanitation', Journal of Development Economics 135: 235-54

Little, M. et al. (2021) 'Effectiveness of Cash-Plus Programmes on Early Childhood Outcomes Compared to Cash Transfers Alone: A Systematic Review and Meta-Analysis in Low- and Middle-Income Countries', PLoS Medicine 18.9: e1003698

Mahon, T. and Fernandes, M. (2010) 'Menstrual Hygiene in South Asia: A Neglected Issue for WASH (Water, Sanitation and Hygiene) Programmes', Gender and Development 18.1: 99-113

Mara, D.; Lane, J.; Scott, B. and Trouba, D. (2010) 'Sanitation and Health', PLoS Medicine 7.11: e1000363

Myers, J. (2014) 'Water, Sanitation and Hygiene Services Beyond 2015: Improving Access and Sustainability', Proceedings of the 38th WEDC International Conference, Loughborough University, Loughborough, UK, 27-31 July 2015

Myers, J.; Maule, L.; Gnilo, M.; Chambers, R. and Cavill, S. (2017) 'Supporting the Least Able Throughout the CLTS Process', CLTS Knowledge Hub Learning Brief 3, Brighton: Institute of Development Studies (accessed 19 January 2022)

Narzetti, D.A. and Marques, R.C. (2020) 'Models of Subsidies for Water and Sanitation Services for Vulnerable People in South American Countries: Lessons for Brazil', Water 12.7: 1976

Palermo, T.M. et al. (2019) 'Impact Evaluation of a Social Protection Programme Paired with Fee Waivers on Enrolment in Ghana's National Health Insurance Scheme', BMJ Open 9.11: 1-10

Piarroux, R. and Frerichs, R.R. (2015) 'Cholera and Blame in Haiti', The Lancet Correspondence 15.12: 1380-81

Quisumbing, A.R. et al. (2020) 'Randomized Controlled Trials of Multi-Sectoral Programs: Lessons from Development Research', World Development 127: 104822

Radin, M. et al. (2020) 'Benefits and Costs of Rural Sanitation Interventions in Ghana', Journal of Water, Sanitation and Hygiene for Development 10.4: 724-43 
Comprehensive Social Protection Programming: What is the Potential for Improving Sanitation Outcomes?

Renzaho, A. et al. (2018) 'Impact of a Multidimensional Child Cash Grant Programme on Water, Sanitation and Hygiene in Nepal', Journal of Water, Sanitation and Hygiene for Development 8.3: 520-32

Robinson, A. and Gnilo, M. (2016) 'Promoting Choice: Smart Finance for Rural Sanitation Development', in P. Bongartz, N. Vernon and J. Fox (eds), Sustainable Sanitation for All: Experiences, Challenges, and Innovations, Rugby: Practical Action Publishing

Roelen, K. and Devereux, S. (2019) 'Money and the Message: The Role of Training and Coaching in Graduation Programming', Journal of Development Studies 55.6: 1121-39

Roelen, K.; Sherer, M. and Leon-Himmelstine, C. (2020) 'The Role of Graduation Programming in Promoting Early Childhood Development: An Overview of the Evidence', Journal of the British Academy 8. Supp.2: $133-61$

Roelen, K.; Kim, S.K.; Barnett, I. and Chanchani, D. (2019) Pathways to Stronger Futures in Haiti: The Role of Graduation Programming in Promoting Early Childhood Development, Research Report, Brighton: Institute of Development Studies

Roelen, K. et al. (2017) How to Make 'Cash Plus' Work: Linking Cash Transfers to Services and Sectors, Innocenti Working Paper 2017-10, Florence: UNICEF Office of Research

Rosenbaum, P.R. and Rubin, D.B. (1983) 'The Central Role of the Propensity Score in Observational Studies for Causal Effects', Biometrika 70.1: 41-55

Transfer Project (2018) Ujana Salama: Cash Plus Model on Youth Well-Being and Safe, Healthy Transitions: Study Design Overview and Baseline Findings, Tanzania Cash Plus Evaluation Team, North Carolina: Transfer Project

UN (2021a) Target 6.2 - Sanitation and Hygiene, UN Water (accessed 19 January 2022)

UN (2021b) Indicator 6.2.1a - Sanitation, UN Water (accessed 19 January 2022)

UN (2021c) Indicator 6.2.1b - Hygiene, UN Water (accessed 19 January 2022)

UNDESA (2021) Sustainable Development, United Nations Department of Economic and Social Affairs (accessed 19 January 2022)

UNDP (2019) Human Development Report 2019. Beyond Income, Beyond Averages, Beyond Today: Inequalities in Human Development in the 21st Century, New York NY: United Nations Development Programme

UNDP (2017) Human Development Report 2017: Human Development for Everyone, New York NY: United Nations Development Programme

UNICEF (2019) UNICEF's Global Social Protection Programme Framework, New York NY: United Nations Children's Fund

UNICEF and WHO (2020) State of the World's Sanitation: An Urgent Call to Transform Sanitation for Better Health, Environments, Economies and Societies, New York NY: United Nations Children's Fund and World Health Organization

UNRISD (2016) 'Sanitation and Social Protection: A Human Rights-Based Approach', Issue Brief 4, Geneva: United Nations Research Institute for Social Development

WHO (2016) Annex 2. Safely Managed Sanitation Services (accessed 19 January 2022)

World Bank (2021) Haiti: Towards the Elimination of Cholera, 7 April (accessed 23 September 2021)

World Bank (2020) World Bank Supports COVID-19 Response and Increased Resilience to Health Shocks and Natural Hazards in Haiti, press release, World Bank (accessed 12 January 2022)

World Bank (2018) 'Poverty and Equity Brief: Haiti', Washington DC: World Bank 


\section{(2) institute of development \\ studies}

Delivering world-class research, learning and teaching that transforms the knowledge, action and leadership needed for more equitable and sustainable development globally.

Institute of Development Studies

Library Road

Brighton, BN1 9RE

United Kingdom

+44 (0)1273606261

ids.ac.uk

Charity Registration Number 306371

Charitable Company Number 877338

(C) Institute of Development Studies 2022 